\title{
Work and fertility in Taiwan: How women's and men's career sequences associate with fertility outcomes?
}

December 17, 2021

\author{
Forthcoming in Longitudinal and Life Course Studies \\ (Please cite the publisher-authenticated version) \\ Chen-Hao Hsu \\ Department of Sociology, University of Bamberg, Germany \\ chen-hao.hsu@uni-bamberg.de
}

\begin{abstract}
There has been much debate over the micro-level relationship between employment situations and fertility in Europe and Northern America. However, related research in East Asia is scant, although countries in this region have some of the lowest fertility rates in the world. Moreover, most studies analyze the employment-fertility relationship from a static perspective and only for women, which underemphasizes life-course dynamics and gender heterogeneity of employment careers and their fertility implications. Drawing on retrospective data from the 2017 Taiwan Social Change Survey (TSCS), this study explores women's and men's career trajectories between ages 18 and 40 in Taiwan using sequence cluster analyses. It also examines how career variations associate with different timing and quantum of birth. Empirical results show that economically inactive women experience faster motherhood transitions and have more children by age 40 than women with stable full-time careers. For men, having an unstable career associates with slower fatherhood transitions and a lower number of children. For both genders, self-employed people are the earliest in parenthood transitions and have the highest number of children by midlife. Our findings demonstrate sharp gender contrasts in employment careers and their diversified fertility implications in low-fertility Taiwan.

Key words: Fertility, Employment Instability, Self-employment, Sequence Analysis, East Asia

\section{Acknowledgment words:}

(C) [Hsu, C.-H., 2021]. This is a post-peer-review, pre-copy edited manuscript accepted by Longitudinal and Life Course Studies, DOI: 10.1332/175795921X16379265590317. The definitive publisher-authenticated version will be available online soon. Data of this research are provided by the Survey Research Data Archive, Academia Sinica, Taiwan. The author thanks Michael Gebel, Jonathan Latner, Sophia Fauser, Sonja Scheuring, Maye Samy, and Luis Ortiz for their insightful comments on the earlier version of this paper.
\end{abstract}




\section{Introduction}

The demographic transition in East Asia has been fueled by families' shifting economic foundations (Raymo et al., 2015). Central to this discussion is the micro-level relationship between men's and women's employment conditions and their fertility. Despite the rapid modernization and industrialization in East Asia, social expectations on men's and women's work-family roles remain rigidly stratified following the Confucianism family model, where male-breadwinners and female-homemakers are still the norms (Bumpass et al., 2009; Cheng, 2020). Given such context, increased employment opportunities for women and the deteriorated career stability for men might contribute to the significant postponement and reduction of fertility (McDonald, 2009). A few East-Asian studies have empirically examined the impacts of employment situations on fertility in Japan and South Korea. In general, men who are unemployed or employed in non-standard positions are more likely to delay fatherhood transition, stay childless, or have fewer children (Piotrowski et al., 2018; Raymo and Shibata, 2017). In contrast, women who are highly attached to the labor market are often linked to delayed family formation and lower marital fertility (Brinton and Oh, 2019; Jones, 2007; Raymo and Shibata, 2017).

In a broader literature context beyond Asia, many studies in Europe have discussed how different forms of employment instability, which primarily manifests as being unemployed or non-standard employed, affect people's birth timing and quantum (Alderotti et al., 2021). Most researchers used event history models or discrete-time logit/probit regressions to examine whether the transition hazards or the likelihood of a specific birth differ across states of employment (Adsera, 2011b; Blossfeld and Mills, 2005; Kreyenfeld, 2010; Pailhé and Solaz, 2012; Piotrowski et al., 2018; Raymo and Shibata, 2017; Vignoli et al., 2016). While these studies provide rich insights to test the instantaneous causal relationship between employment 
and childbirth, their focus on the snapshot of employment "states" or "transitions" in crosssectional time points tend to overlook how people's careers are unfolding in real life (Abbott, 2016; Aisenbrey and Fasang, 2017). Also, the isolated investigation on each birth transition would not allow an examination of how people's holistic employment careers are associated with their complete fertility histories.

According to family theorists, individuals' work and fertility trajectories are unfolding in an interdependent process over time, indicating that the timing, duration, and sequencing of employment states in discrete time points should be examined as a whole package to understand its long-term implications on people's fertility histories (Buhr and Huinink, 2014; Huinink and Feldhaus, 2009; Huinink and Kohli, 2014). However, these theoretical insights have rarely been tested using holistic approaches until recently (Busetta et al., 2019; Ciganda, 2015; Özcan et al., 2010; Pailhé and Solaz, 2012).

Drawing on the strengths of multiple methods, this study contributes to the emerging literature of investigating work-family relationships from a life course perspective (Huinink and Kohli, 2014). The study is the first to typologize women's and men's major career tracks in Taiwan using sequence analyses and to investigate career differentials in the timing and quantum of fertility until midlife. Its findings for ultra-low-fertility Taiwan complement previous EastAsian work-family research by demonstrating the gendered career patterns and their fertility implications in multiple aspects (Brinton, 2001; Jones, 2019; McDonald, 2009; Yu, 2009).

\section{Background}

\section{Theoretical relationship between employment and fertility}

The micro-level relationship between individuals' employment and fertility outcomes is a prominent research topic among economists, sociologists, and demographers. Previous studies 
have shown that such a relationship could be bi-directional, namely, people's employment situations may affect their fertility behaviors and vice versa (Matysiak, 2011; Matysiak and Vignoli, 2008). With an aim to understand the economic and sociological factors behind Taiwan's low fertility phenomenon, this study pins down to the discussions on how people's employment situations affect fertility.

An economic perspective from the New Home Economics (Becker, 1991) argues that people's fertility is contingent on the costs and benefits of children. It assumes that raising children is "costly" for parents in terms of pecuniary and non-pecuniary resources, such as time and energy. Since income is decided primarily by one's employment status, this theory predicts that stable employment may enhance the demand for children (i.e., the positive income effect) because stably employed individuals can afford more children under the same costs comparing to those without a stable job. On the other hand, stable employment and its extended utilities, including higher economic and social status, could raise the price of time and the opportunity costs of children, thereby reducing one's childbirth demand (i.e., the negative substitution effect). Whether employment affects fertility positively or negatively depends on which effect is dominating. Given a traditional gender division of labor, where men are the primary income provider of a household, the New Home Economics theory predicts gender-asymmetric effects of employment on fertility (Becker, 1991). That is, the positive income effect of employment usually dominates men's fertility decisions, leading to a positive relationship between employment stability and male fertility. Among women, fertility decisions are affected more by the substitution effect of employment, leading to a negative relationship between female employment and fertility outcomes. 
Sociologists tackle the issue from another perspective, emphasizing the impacts of employment instability on fertility and how they interact with the gendered social norms. On the one hand, the theory of career-marriage dynamics (Oppenheimer, 1988) argues that unstable employment leads to uncertain career prospects, which impedes individual's chance of matching an ideal partner in the marriage market. In addition, highly differentiated gender roles may foster gender differences in entering marriage or becoming parents when coping with career uncertainty. As a result, unemployment or unstable employment status makes a man economically unattractive (Oppenheimer et al., 1997), which delays his family formation (Oppenheimer et al., 1997; Vignoli et al., 2016). On the other hand, Friedman and colleagues (1994) propose the uncertainty reduction theory, which emphasizes the socio-psychological benefits of parenthood and argues that having children could serve as a strategy to counter the external uncertainty in employment conditions. In contrast to Oppenheimer's focus on men's career instability, the uncertainty reduction theory focuses on women and argues that women who confront unfavorable employment prospects may choose motherhood as an alternative career to secure their self-confidence and social status, particularly in societies that appraise the intrinsic value of family and parenthood.

While these theories explain the work-fertility linkage through different mechanisms, they have similar predictions regarding the fertility impacts of employment stability, especially in a context where familistic gender norms are dominating. Given the gendered role expectation in familistic countries, both Becker's (1991) and Oppenheimer's $(1988,1997)$ theories predict that stable employment enhances men's fatherhood transition and fertility. On the other hand, Becker's (1991) and Friedman's (1994) theories indicate that women's fertility behaviors are negatively associated with employment stability. 


\section{Empirical research on the employment-fertility relationship}

Empirical evidence on the micro-level relationship between employment stability and fertility is inconclusive and varies across countries (Blossfeld and Mills, 2005; Matysiak and Vignoli, 2008). In conservative or familistic countries such as Germany, Italy, and Japan, findings for men generally support the theoretical predictions: stable employment, comparing to unstable employment, enhances men's fertility (Blossfeld and Mills, 2005; Hilgeman and Butts, 2009; Piotrowski et al., 2018; Raymo and Shibata, 2017). For women in conservative or familistic countries, stable employment has fertility-depressing effects when it is compared against unemployment (Matysiak and Vignoli, 2008, 2013), while it has fertility-enhancing effects when it is compared against non-standard time-limited employment (Alderotti et al., 2021). However, most previous studies only investigate the cross-sectional employment-fertility relationship at a specific point of lifetime. Such a static perspective cannot fully capture the life-course dynamics

of employment careers and their long-term associations with multiple fertility outcomes (Abbott, 2016; Aisenbrey and Fasang, 2017; Bernardi et al., 2019).

Life-course theories argue that individuals unfold their life courses according to experiences accumulated in the past, choices and constraints encountered in the present, and life prospects anticipated for the future (Abbott, 2016; Elder et al., 2003; Mayer, 2009). According to Bernardi et al. (2019), a life course is conceptualized as a multidimensional behavioral process marked by sequences of events and social transitions that individuals enact over time.

Over the lifetime, some people have stable employment experiences in full-time standard positions or self-employment, while some may have interrupted careers at some ages or switching between different career tracks; still others may work continuously in precarious jobs or stay inactive to the labor market. Each employment trajectory involves different timing and 
sequencing of employment experiences. Given such complexity, it is rather ambiguous to classify one's employment pattern as "stable" or "unstable" based only on one or several discrete-time employment states or transitions (Biemann et al., 2012; Devillanova et al., 2019; Fuller and Stecy-Hildebrandt, 2015). For example, using sequence analyses, researchers show that a seemingly uncertain employment state in the short term may lead to diverse career pathways in the long run (Brzinsky-Fay, 2010; Fauser, 2020; Fuller and Stecy-Hildebrandt, 2015; McVicar et al., 2019; Reichenberg and Berglund, 2019): some people follow the "stepping-stone" pathway where earlier temporary employment, part-time employment, or unemployment leads to stable, full-time employment in the long run, while other workers in nonstandard employment positions are "trapped" in a labor market dead-end.

Fertility histories are also structured in a sequential timetable in modern societies (Huinink and Feldhaus, 2009; Huinink and Kohli, 2014). Childbirth decisions are not made in isolation. The timing, spacing, and the number of births over the life course are contingent on past fertility experiences (Buhr and Huinink, 2014; Huinink and Feldhaus, 2009). More importantly, fertility life courses have interdependent relationships with other life domains, particularly with one's work and employment careers (Aisenbrey and Fasang, 2017; Krüger and Levy, 2001; Pollock, 2007; Vignoli et al., 2020). In this regard, people's fertility histories are shaped not only by "sequential institutionalization," but also by "simultaneous institutionalization," in which fertility and employment life courses are unfolding simultaneously (Huinink and Kohli, 2014; Krüger and Levy, 2001).

Drawing on the life-course perspective, I define people's "career" as a sequence of interdependent employment states evolving over time (Biemann et al., 2012; Pollock, 2007; Simonson et al., 2011). Following previous research on the objective relationship between 
employment uncertainty/instability and fertility (Kreyenfeld et al., 2012), I define an "unstable" career as having a sequence of multiple incidences or long duration in unemployment or nonstandard employment states (Kalleberg, 2009), which contrasts a "stable" employment career featuring continuous employment in standard full-time jobs.

An unstable employment career is considered detrimental to people's parenthood transition (Blossfeld and Mills, 2005; Kreyenfeld et al., 2012). Using multi-channel sequence analyses, several studies showed that a disrupted or low-prestige employment career has a lifecourse affinity with delayed family formation and parenthood transition (Aisenbrey and Fasang, 2017; Simonson et al., 2011; Sirniö et al., 2017). However, the complex associations between careers and fertility outcomes are "gendered" (Krüger and Levy, 2001), particularly in conservative and familistic countries (Blossfeld and Mills, 2005). Studying the career pathways to childlessness, research in Italy found that most childless women had a stable rather than an interrupted or inactive employment career (Mynarska et al., 2015; Tocchioni, 2018), while childless men's career pathways were more diversified (Tocchioni, 2018). An uninterrupted employment career increased men's likelihood of fatherhood but decreased women's likelihood of motherhood in the Netherlands (Keizer et al., 2008). Among Italian couples, husbands' persistent joblessness also played a more decisive role in inhibiting wives' intentions to have further childbirth (Busetta et al., 2019).

Several studies considered the impacts of employment stability not only on one specific birth transition but also on the total number of children people ultimately have (i.e., the quantum effect). In Germany, Auer and Danzer (2016) found that entering the labor market with a fixedterm contract delayed women's age at first birth and reduced their total number of children within ten years since graduation, while no significant effect in these two aspects was found for 
men. Focusing on the duration of unemployment, Pailhé and Solaz (2012) found that long-term unemployment negatively affected men's but not women's complete fertility (i.e., the number of children by age 40) in France. By examining people's employment sequences, Ciganda (2015) found that having an unstable career delayed men's fatherhood transition and reduced the number of children for both men and women in France. While the gendered patterns found are inconclusive, all these studies point to the need for a holistic investigation into the gendered employment-fertility relationship because the impacts of employment stability may extend far beyond the first parenthood transition.

Aside from the dichotomy between the typically stable and unstable careers, another prominent career type in familistic countries is self-employment. Empirical studies show that self-employment has distinct implications on fertility across different countries (Adsera, 2011a; Begall and Mills, 2013; Del Boca et al., 2005; Köppen et al., 2017; Matysiak and Mynarska, 2020; Noseleit, 2014; Sinyavskaya and Billingsley, 2015; Tocchioni, 2018). Comparing to workers of stable full-time employment, self-employees might on the one hand enjoy higher flexibility needed to reconcile work with family, while on the other hand suffer from higher employment uncertainty because their jobs are not protected by contracts. Self-employment also provides career alternatives for many people who have difficulty finding dependent employment jobs, especially in familistic welfare regimes like Southern Europe during an economic downturn (Adsera, 2011a). Therefore, researchers have suggested that self-employment could enhance women's fertility when institutional support for combining work and childcare is weak (Matysiak and Mynarska, 2020). Also, in a context where people's selection into selfemployment involves more rational incentives, such as to secure and mobilize family resources, 
this career choice may serve as an ideal package to combine work with family (Anthias and Mehta, 2003).

\section{The Taiwanese context}

Taiwan is well known for its currently ultra-low fertility rates and late adulthood transitions in the demographic literature (Cheng, 2020; Goldstein et al., 2009; Jones, 2019; Nauck et al., 2017). During the post-WWII industrialization, Taiwan's period total fertility rate (PTFR) has dropped from seven children in 1951 to the replacement level of 2.1 children in 1983. Following the Globalization trend in the 1990s, the PTFR has further declined to below the level of 1.3 children since 2003. Meanwhile, the social and economic systems have changed fundamentally, particularly in two aspects: (1) the dramatic increase in female labor force participation in paid jobs (Gietel-Basten, 2019; Yu, 2009), and (2) the emergence of precarious and uncertain employment relationships (Chen et al., 2003; Hsiao, 2013; Kalleberg and Hewison, 2013). Given such a context where the Second Demographic Transition meets Globalization (Mills and Blossfeld, 2013), it is theoretically crucial to investigate whether and how Taiwanese women and men's fertility behaviors are associated with their employment careers. Surprisingly, empirical research in Taiwan on this micro-level relationship is scant.

Taiwan, together with Japan and South Korea in East Asia, are usually ranked among the countries with the most inadequate conditions for combining work with family (Frejka et al., 2010; Gauthier, 2016; Jones, 2007; McDonald, 2009). This is especially true for Taiwanese women because childcare and housework tasks are conventionally considered as mothers' responsibilities (Cheng, 2020; Cheng \& Hsu, 2020). Moreover, work-family reconciliation is weakly supported by public policies (Gauthier, 2016; Tsai, 2012). A two-year unpaid parental leave was introduced in 2002 in the Act of Gender Equality in Employment. In 2009, the Amendment of the Employment 
Insurance Act further added a six-month childcare cash benefit for parental leave takers. However, taking parental leaves is not common among Taiwanese until very recently. From 2009 to 2018, the percentage of eligible female workers receiving childcare benefits during their leaves increased from $24.3 \%$ to $77.3 \%$, while the male uptake rate remained below 9\% in 2018 (Ministry of Labour, 2020; author's calculation). Meanwhile, the enrollment rate in public-supported childcare facilities is extremely low in Taiwan, especially for infants and toddlers below age three. From 2005 to 2018, the enrollment rate in early education and childcare for children below age three increased from $0.5 \%$ to $11.5 \%$ (Ministry of Education, 2020; Ministry of Health and Welfare, 2020; author's calculation). Given the context, the "mismatch" between women's rising demand for work-family reconciliation and the stagnated policy development of public childcare and parental leaves is argued to withhold people's childbirth in Taiwan (Gauthier, 2016).

An earlier study has found that "current employment away from home has a significant effect on children ever born for Taiwanese women, depressing fertility by an average of 0.25 children" (Speare Jr. et al., 1973: 332). These results might reflect Taiwanese women's tendency to avoid the conflicts between work and childrearing by delaying motherhood or by spacing each parity transition at greater intervals. Such findings were supported by another study using data from a 1980 survey (Stokes and Hsieh, 1983), which found that married women who were always employed had the lowest number of children ever born. Using data from a 1989 survey, Wu and Chuang (2018) found that longer job tenure and higher labor market attachment before the first birth may delay married women's first birth transition.

While these studies provided valuable insights, their findings were relatively outdated and did not capture the employment-fertility relationship in Taiwan after 1989. They also did not discuss the negative impact of unstable employment on men's fertility, which has been a crucial 
fertility-depressing factor in other East-Asian countries like Japan (Piotrowski et al., 2018; Raymo and Shibata, 2017). Most importantly, previous studies in Taiwan failed to examine the dynamic development of people's employment careers and fertility outcomes from a life-course perspective. The present paper adds to prior studies by using sequence analyses to explore Taiwanese women and men's major career trajectories before midlife and to examine how these careers are related to different timing and quantum of fertility by age 40 .

\section{Hypotheses}

By incorporating the Taiwanese case into the theoretical framework discussed above, I formulate several hypotheses on the relative timing of parenthood transitions and the quantum of fertility across different career types. Specifically, I predict:

Hypotheses 1a \& 1b: Taiwanese women who have a stable employment career in standard full-time jobs, compared to women of unstable careers, are associated with a slower motherhood transition (Hypothesis la) and a lower number of children by midlife (Hypothesis 1b).

Hypotheses $2 a \& 2 b:$ Taiwanese men who have a stable employment career in standard full-time jobs, compared to men of unstable careers, are associated with an earlier fatherhood transition (Hypothesis 2a) and a higher number of children by midlife (Hypothesis 2b).

Regarding the fertility implications of self-employment for women, I expect:

Hypotheses $3 a \& 3 b$ : Taiwanese women who have a self-employed career, compared to women in the standard full-time track, are associated with an earlier motherhood transition (Hypothesis 3a) and a higher number of children by midlife (Hypothesis 3b). 
This prediction reflects the difficulties for career-oriented women to combine work with family in a standard employment position because childcare supports from public policies and husbands' domestic help are generally lacking (Cheng and Hsu, 2020; Gauthier, 2016).

For men, many male self-employees in Taiwan are either the patrilineal descendants of family firms or first-generation entrepreneurs starting their own business with the help of family resources. In such context, self-employed men might have higher economic status than the majority of firm-employed men. They might also have superiority in mobilizing non-monetary family resources for childcare (Lu, 2001). Finally, due to the lack of employment protection laws in Taiwan until recently, dependent employees in the private sector do not necessarily have higher job stability than self-employees (Yu and Su, 2009). Therefore, I expect:

Hypotheses $4 a \& 4 b$ : Taiwanese men who have a self-employed career, compared to men in the standard full-time track, are associated with an earlier fatherhood transition (Hypothesis 4a) and a higher number of children by midlife (Hypothesis 4b).

\section{Method}

\section{Data}

This study uses data from the 2017 Taiwan Social Change Survey (TSCS 2017, Fu, 2019). The TSCS is a cross-sectional survey project tracking the long-term trends of social changes in Taiwan. Since its first wave completed in 1985, the TSCS has accumulated over 60 surveys over the past 30 years. It applies survey modules comparable to many international survey projects, such as the ISSP and the EASS. The 2017 TSCS data comprise a nationally representative sample of 1,917 Taiwanese adults aged 18 to 70. It includes retrospective information on individuals' education, work, partnership, and fertility histories. To construct individuals' employment and family biographies between ages 18 and 40, I restrict the analytical sample to those aged above 40 by 
2017. After excluding 87 people without complete records in education, employment, or fertility histories, the final sample comprises 507 women and 585 men born between 1946 and 1977.

\section{Analytical strategy, variables, and measurements}

To explore the major career trajectories and their linkage to the timing and the quantum of fertility, I propose an analytical framework combining multiple methods including sequence analysis, survival analysis, and multivariate regressions. Firstly, I use sequence and cluster analyses to identify typical employment careers for Taiwanese women and men. Individuals' yearly employment and education histories across 23 years from age 18 until age 40 are reconstructed as holistic career sequences. For women, I consider five distinct states of activities in each time point: (1) in education, (2) self-employment and family workers (i.e., work in family business), (3) non-standard employment, including part-time workers, temporary/fixedterm contractors, and dispatched workers, ${ }^{1}$ (4) full-time standard employment, and (5) nonemployment. ${ }^{2}$ For men, I consider an additional state of (6) in military services because military services for up to three years are mandatory for male citizens in Taiwan. Using these states, I create career sequences for each individual and use the Hamming Distance algorithm (HAM) to calculate the pairwise distances matrix between sequences. Comparing to the commonly used Optimal Matching algorithm, HAM is more sensitive to dissimilarities in the timing and positioning of states and transitions (Aisenbrey \& Fasang, 2010; Studer \& Ritschard, 2016).

\footnotetext{
${ }^{1}$ It is worth noticing that employment subcategories defined as "non-standard" or "precarious" in the Taiwanese context may differ from those in Western countries (Hsiao et al., 2015). The inclusion of subcategories in our nonstandard employment state follows Hsiao's (2013) contextual definition.

${ }^{2}$ Due to data limitation, I cannot directly identify whether a non-employment state in a retrospective year is resulted from one's involuntary unemployment or from his/her voluntary labor market inactivity. Both states in the focal analyses are categorized as non-employment. In a measurement sensitivity test, I create a proxy state of inactivity and reassign employment years into this category when individuals stay non-employed for consecutive three years. Sensitivity analyses using this proxy state in the sequences show similar clustering results in terms of their substantive social meanings. Since using the ad hoc proxy state does not add empirical values to my career typology, I adhere to the original state measurement of non-employment.
} 
Placing more emphasis on timing is theoretically justified because life course research has shown that the timing of school-to-work transitions and early-career work development is particularly important in shaping individuals' family lives in both Europe and East Asia (Buchmann \& Kriesi, 2011; Yeung \& Alipio, 2013). ${ }^{3}$

After obtaining the distances matrix, I deploy the partitioning around medoids (PAM) procedure for clustering (Kaufman \& Rousseeuw, 2009). This method aims to obtain the best partitioning of a dataset into a predefined number of $k$ groups. Through an iterative "swapping" procedure, PAM seeks to minimize the weighted sum of distances between every sequence and the medoids - the "best representative" sequences of each group (see Kaufman \& Rousseeuw (2009) for technical details). Comparing to the popular Ward hierarchical clustering method, the PAM method has a better global-level clustering performance and generally renders higher between-cluster dissimilarities (Studer, 2013). However, a drawback of the conventional PAM method is that its clustering results are sensitive to the initial choice of medoids, which are not always optimal. To overcome this limitation, I follow Studer's (2013) suggestions to initialize the PAM algorithm using the result of the Ward procedure (i.e., the PAM+Ward procedure). ${ }^{4}$ Because previous studies for Taiwan did not offer any reference number of career types, I follow the rule of thumb in empirical sequence research: determining the number of clusters based on

\footnotetext{
${ }^{3}$ In a sensitivity analysis presented in the supplementary material S1, I use the Optimal Matching of spells (OMspell) algorithm with an expansion cost $\mathrm{e}=0.5$ to calculate the distances matrix. Comparing to HAM, OMspell is more sensitive to the duration and the sequencing of spells (Studer \& Ritschard, 2016). It thus serves as the benchmark algorithm to test whether shifting the theoretical focus from timing to the duration and sequencing of states will significantly change the clustering results. From a substantive sense, the clustering results from OMspell are similar to those from HAM. However, the clustering performance of OMspell, measured by several sequence partitioning indices, are inferior to HAM (see Table A2 for the comparison of global-level and cluster-specific ASWs between these two solutions).

${ }^{4}$ A sensitivity analysis (not shown, available on request) shows that using the conventional Ward hierarchical clustering yields similar results in terms of the substantive attributes of the identified clusters. However, from a statistical point of view, the clustering results of the PAM+Ward procedure obviously outperform the Ward method in the partitioning quality measures. Table A2's note compares the performances of statistical quality measures across different methods.
} 
statistical quality measures and theoretical meaningfulness (i.e., the construct validity) of different cluster solutions (Aisenbrey and Fasang, 2010; Fuller and Stecy-Hildebrandt, 2015). Using this strategy, I identify four clusters for women and three clusters for men as optimal. A battery of partitioning quality indicators across different clustering solutions are presented in Figure A1 (Piccarreta \& Struffolino, 2019; Studer, 2013), including the Average Silhouette Width (ASW), the Point Biserial Correlation (PBC), and the Hubert's C (HC). Taken together, I argue that women's four-cluster and men's five-cluster solutions using the HAM algorithm in a PAM+Ward procedure have high validity representing the major career typology in Taiwan.

To explore the career differentials in fertility timing, I calculate the cumulative hazards of the first three parenthood transitions using the Nelson-Aalen estimators by career. The hazard (rate) of transition is identified as the conditional probability of a birth event occurring at time $t_{i}$, given that there has been no such an event before $t_{i}$. In discrete time, the hazard function is given by $r\left(t_{i}\right)=\operatorname{Pr}\left(T=t_{i} \mid T \geq t_{i}\right)=\frac{f\left(t_{i}\right)}{S\left(t_{i-1}\right)}$, which is the probability function of time duration from the initial state to the birth event divided by the survivor function up to the time point just before time $t_{i}$. Presenting cumulative transition hazards using the Nelson-Aalen estimator is informative in describing the (timing) pace of fertility because the cumulative form of transition hazards implies the duration of waiting time for the occurrence of a birth transition (Mills, 2010).

To further investigate whether one's fertility quantum is affected by having a different career type, I specify a count model of a person $i$ 's number of children ever born $y_{i}$ by age 40 using the following equation:

$$
y_{i}=\boldsymbol{X}_{i} \boldsymbol{\beta}+\boldsymbol{Z}_{i} \boldsymbol{\varphi}+\varepsilon_{i}
$$

where $\boldsymbol{X}_{i}$ denotes the vector of career dummies specified from the sequence cluster analyses. $\boldsymbol{Z}_{i}$ 
is a vector of other covariates used as control variables. $\varepsilon_{i}$ denotes the unobserved individual error term (idiosyncratic errors). The parameters $\boldsymbol{\beta}$ thus present the estimated fertility quantum effects of having a specific career type comparing to the reference career, conditioning on the control variables. Following Auer and Danzer (2016), I use Poisson regressions to estimate the regression coefficients specified in Equation (1) for female and male samples separately. For statistical inferences, I present bootstrapped standard errors with 200 repetitions to account for the possible violation of normal distribution assumptions for residuals in a relatively small sample (Efron \& Tibshirani, 1986; Guan, 2003). ${ }^{5}$

Regression models control for several socio-demographic covariates. Individuals are categorized into three birth cohort categories: cohorts 1946-1957, cohorts 1958-1967, and cohorts 1968-1977. The parental highest educational level measures if at least one of an individual's parents received tertiary education (ISCED levels 5-8). Ethnic minority measures if a person was born in an ethnic minority family, defined as having at least one parent of Taiwanese-Aboriginal or non-Taiwanese backgrounds. Family economic background is measured as a subjective evaluation of one's household financial situation at age 15 relative to other families' using a five-point liker scale, ranging from "much better" to "much worse." For 7 people who have missing data in this variable due to item non-response, I assign them with the median value 3 (which denotes a "fair" family economic background). Finally, in the robustness analysis in Table A3, I additionally control for individuals' highest educational level by age 40 in three categories: primary education (ISCED 0-2), secondary education (ISCED 3-4), and tertiary education (ISCED 5-8). Table A1 in the Appendix presents descriptive statistics of these

\footnotetext{
${ }^{5}$ A sensitivity test using the robust standard errors (not shown, available on request) shows very similar results for statistical inferences.
} 
variables for each subsample.

Sequence and cluster analyses in the first part are performed using the software $\mathrm{R}$ (version 4.0.2) and the R package TraMineR (Gabadinho et al., 2011). Survival analysis and multivariate regressions are performed using the software STATA (version 14.2).

Figure 1: Clusters of employment careers from age 18 to age 40 for women and men

\section{(a) Women}

Std. FT career $(50.3 \%)$

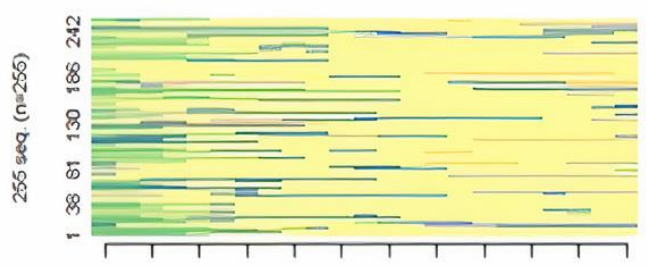

Inactive (15.6\%)

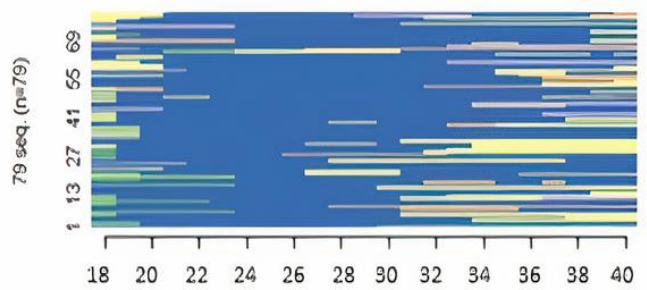

Interrupted career (18.9\%)

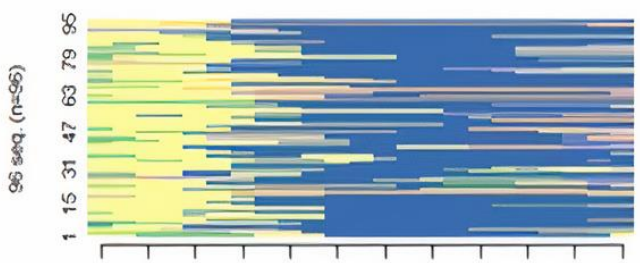

Selfoemployed (15.2\%)

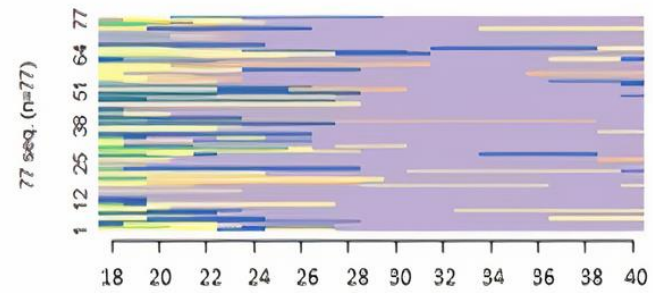

(b) Men

Std. FT career $(64.4 \%)$

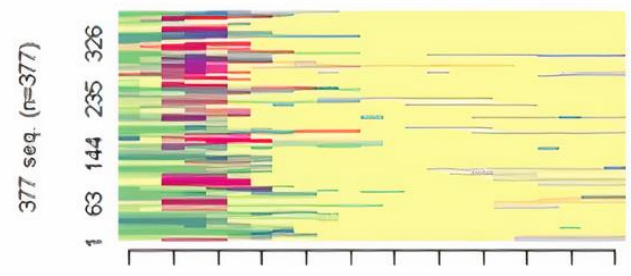

Unstable career $(9.2 \%)$

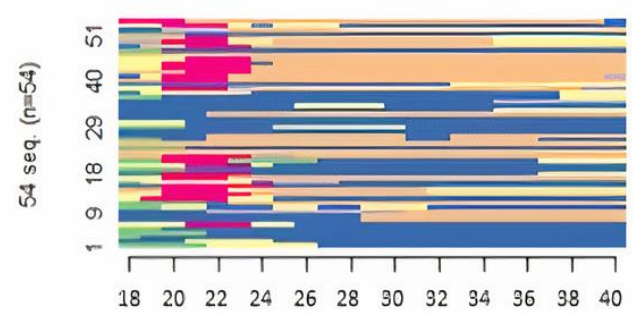

Self-employed (26.3\%)

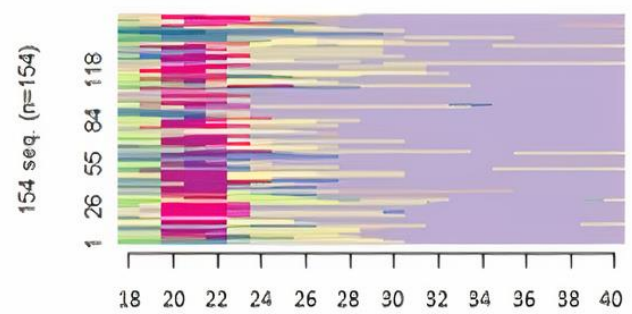

Education

Self-employment

$\square$ Non-std employment

$\square$ Std FT employment

Non-employment

Military service 


\section{Results}

\section{Women's and men's career typologies in Taiwan}

Figure 1 graphically presents the sequence-clustering results of major career trajectories for Taiwanese women and men. Figures A2 and A3 in the Appendix present the Silhouette widths of sequences by cluster for women and men. Within career clusters, year durations in each state are presented in Table 1. For women, the most prevalent pattern is working mostly in a standard full-time career (50.3\% of women). Women in this career track spend a relatively long time in education (1.86 years) after turning 18 years old. This marks the relatively high educational level of this group — on average tertiary degree — comparing to other women. After graduation, these women spend on average 18.07 years in standard full-time employment positions until midlife. There are only short career interruptions up to 1.84 years among these women, and they don't frequently switch to other employment tracks. The second cluster, comprising $18.9 \%$ of women, is best described as interrupted careers. ${ }^{6}$ The majority of these women start their careers in standard full-time positions for about 7 years. After age 25, most of these women quit employment entirely or switch to more flexible self- or non-standard employment tracks. The emergence of this interrupted career pattern in East Asia is likely due to women's career adjustment upon family formation in order to reconcile work-family role conflicts (Raymo et al., 2015; Yu, 2009). The third pattern is called (economically) inactive, comprising $15.6 \%$ women who have been non-employed for 17.77 years out of the first 23 years after age 18 . The fourth female career pattern, the self-employed, is featured by an extended time duration in self- or family-employment positions before midlife (on average 16.3 years).

\footnotetext{
${ }^{6}$ According to Figure A2, the average Silhouette width of this cluster is 0.19 , which indicates a very weak structure and a low within-cluster homogeneity (Studer, 2013). Against the background, one should be cautious not to overinterpret the fertility results related to this interrupted career cluster.
} 
For men, my results indicate a three-cluster solution. The most prevalent male career pattern is having a standard full-time career (64.4\%). Like what I found for women, men in the standard full-time track have longer years in education (2.49 years) comparing to other men. The second pattern, which is also found for women, is being self-employed (26.3\%) for most of the early career. The third pattern for men, best described as unstable careers $(9.2 \%)$, is featured by the combination of long-term non-employment, long-term non-standard employment, or frequent switching between standard and precarious career tracks. Comparing to men in the prior two clusters, men of unstable careers spend more time in either the state of non-standard employment (8.07 years) or non-employment (10 years) after age 18.

Table 1: Year duration in each state by sex and career types, ages $18-40$

\begin{tabular}{lcccccccc}
\hline & $\begin{array}{c}\text { In } \\
\text { education }\end{array}$ & $\begin{array}{c}\text { Self- or } \\
\text { family- } \\
\text { employment }\end{array}$ & $\begin{array}{c}\text { Non- } \\
\text { standard } \\
\text { employment }\end{array}$ & $\begin{array}{c}\text { Standard FT } \\
\text { employment }\end{array}$ & $\begin{array}{c}\text { Non- } \\
\text { employment }\end{array}$ & $\begin{array}{c}\text { Military } \\
\text { service }\end{array}$ & $\begin{array}{c}\text { Total } \\
\text { years }\end{array}$ & $\begin{array}{c}\text { N of } \\
\text { cases }\end{array}$ \\
\hline Women & 1.86 & 0.63 & 0.60 & 18.07 & 1.84 & - & 23 & 255 \\
$\quad$ Standard FT career & 0.78 & 1.19 & 1.58 & 6.99 & 12.46 & - & 23 & 96 \\
$\quad$ Interrupted career & 0.67 & 0.75 & 0.94 & 2.87 & 17.77 & - & 23 & 79 \\
$\quad$ Inactive & 0.49 & 16.30 & 0.75 & 3.03 & 2.43 & - & 23 & 77 \\
$\quad$ Self-employed & & & & & & & & \\
Men & 2.49 & 0.77 & 0.21 & 17.12 & 1.31 & 1.09 & 23 & 377 \\
$\quad$ Standard FT career & 0.84 & 15.23 & 0.20 & 3.69 & 1.34 & 1.70 & 23 & 154 \\
$\quad$ Self-employed & 0.78 & 0.54 & 8.07 & 2.26 & 10.00 & 1.35 & 23 & 54 \\
$\quad$ Unstable career & & & & & & & & \\
\hline
\end{tabular}

The clustering results not only show career heterogeneity among Taiwanese women and men but also indicate career hierarchies in terms of employment stability. Following previous research (Biemann et al., 2012; Fauser, 2020; Fuller and Stecy-Hildebrandt, 2015), I define the standard full-time career as the most "stable" employment career for both women and men, not only because they enjoy better employment and financial protections compared to non-standard workers, but also because their employment might be less influenced by external business cycle compared to self-employees. For men, having an unstable career denotes the least employment 
stability because being trapped in the states of non-employment or non-standard employment signal these men's incapability of establishing a secured employment career (Fuller \& StecyHildebrandt, 2015; McVicar et al., 2019). For women, it is relatively ambiguous to argue whether having an inactive career is more unstable than an interrupted career because the former might simply reflect some women's family-oriented life preferences (Hakim, 2000). Yet, from a life course perspective, economically inactive women obviously have less labor force attachment than women of interrupted careers. Therefore, I assume that inactive women have the least employment stability among Taiwanese women.

\section{Descriptive analyses of the employment-fertility relationships}

Table 2 presents descriptive statistics of the average incidence, timing, and quantum of fertility for Taiwanese women and men across career types. The percentage of standard full-time employed women having at least one birth by age $40(84.7 \%)$ is about 10 percentage points lower than women of other careers, indicating that women of uninterrupted full-time careers are more likely to remain childless by midlife. Moreover, they are also less likely to have the second (70.2\%) and the third births $(26.3 \%)$. Given the later age at first birth and the lower incidence of each birth transition among standard full-time women, they have a relatively low number of children (1.87 children) by age 40 comparing to women of other careers. In contrast, economically inactive women have the highest incidence rates of experiencing all three birth transitions, leading to their highest number of children by age 40 among women ( 3 children).

For men, Table 2 shows that those who have unstable careers are more likely to stay single by age 40 (about $30 \%$ do not have the first birth). Men with unstable careers are also the least likely to have the second (59.3\%) and the third births (25.9\%). Interestingly, the incidence rates of each birth transition are higher among self-employed men than standard full-time male 
employees. The aggregate result is that self-employed men have on average 0.75 more children than unstable-career men and 0.5 more children than standard full-time career men by midlife.

Table 2: Average fertility outcomes by sex and career types, ages 18-40

\begin{tabular}{|c|c|c|c|c|c|c|c|}
\hline & \multicolumn{3}{|c|}{$\begin{array}{l}\text { Incidence rate of childbirth } \\
\text { (\% of entire cluster })\end{array}$} & \multicolumn{3}{|c|}{$\begin{array}{l}\text { Age at childbirth } \\
\text { (given a birth event) }\end{array}$} & \multirow{2}{*}{$\begin{array}{c}\mathrm{N} \text { of } \\
\text { children by } \\
\text { age } 40\end{array}$} \\
\hline & $\begin{array}{c}\text { 1st } \\
\text { birth }\end{array}$ & $\begin{array}{l}\text { 2nd } \\
\text { birth }\end{array}$ & $\begin{array}{c}\text { 3rd } \\
\text { birth }\end{array}$ & $\begin{array}{c}1 \text { st } \\
\text { birth }\end{array}$ & $\begin{array}{l}\text { 2nd } \\
\text { birth }\end{array}$ & $\begin{array}{c}\text { 3rd } \\
\text { birth }\end{array}$ & \\
\hline \multicolumn{8}{|l|}{ Women } \\
\hline Standard FT career & $84.7 \%$ & $70.2 \%$ & $26.3 \%$ & 26.76 & 28.90 & 29.16 & 1.87 \\
\hline Interrupted career & $93.8 \%$ & $91.7 \%$ & $54.2 \%$ & 24.90 & 27.48 & 29.42 & 2.47 \\
\hline Inactive & $94.9 \%$ & $92.4 \%$ & $69.6 \%$ & 21.71 & 24.45 & 26.82 & 3.00 \\
\hline Self-employed & $93.5 \%$ & $87.0 \%$ & $53.2 \%$ & 23.15 & 25.33 & 27.59 & 2.61 \\
\hline \multicolumn{8}{|l|}{ Men } \\
\hline Standard FT career & $86.7 \%$ & $67.4 \%$ & $27.9 \%$ & 29.51 & 31.56 & 32.96 & 1.94 \\
\hline Self-employed & $92.9 \%$ & $82.5 \%$ & $47.4 \%$ & 27.44 & 28.88 & 31.36 & 2.44 \\
\hline Unstable career & $70.4 \%$ & $59.3 \%$ & $25.9 \%$ & 27.42 & 29.36 & 32.40 & 1.69 \\
\hline
\end{tabular}

Note: Birth-specific incidence rates are calculated as the numbers of the specific births divided by the entire cluster sample sizes. Ages at childbirth are calculated as the mean ages of the specific births among those who experienced the birth events.

\section{Employment careers and fertility timing}

To further investigate whether and how people's timing of childbirth differs across career groups over the life course, I use non-parametric Nelson-Aalen estimators to estimate the cumulative hazards of birth transitions for the first three birth events. Figure 2 presents women's results and the log-rank tests for the equality of the survivor functions across groups. Large career differentials in the hazards of (first) motherhood transitions are observed in Figure 2-a according to the log-rank test. Both inactive and self-employed women experience higher transition hazards to motherhood in their early careers comparing to the other two groups. Despite their slower pace to motherhood at the beginning, women with interrupted careers gradually catch up with the former two groups after age 25 and eventually have the same level of cumulative first-birth 
hazards as the prior two groups after the mid-30s. In sharp contrast, standard full-time women not only lag behind other women in terms of motherhood transition during the early lives but also cannot catch up with their pace before midlife. In summary, these findings support Hypotheses 1a and 3a, showing that Taiwanese women who have a stable career in standard fulltime jobs are associated with a slower motherhood transition than women with unstable careers (i.e., inactive women) and self-employed careers.

Figure 2: Nelson-Aalen cumulative hazard estimates and log-rank tests of group differences across women's career types by birth transitions.

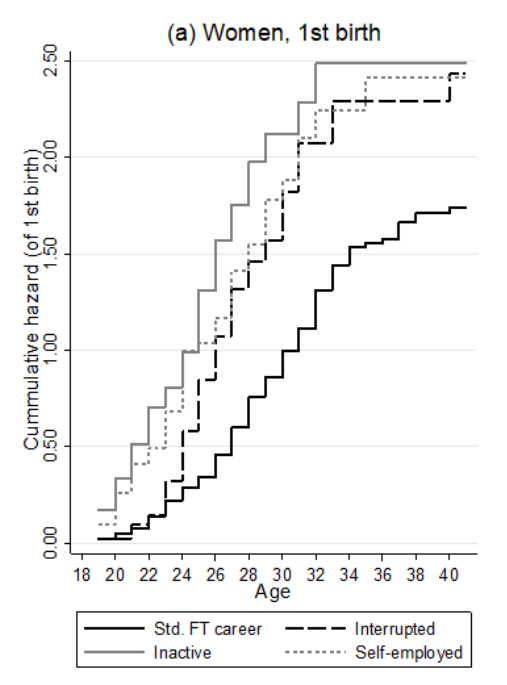

Log-rank test for equality of survivor functions

\begin{tabular}{l|ccc} 
& $\begin{array}{c}\text { Events } \\
\text { observed }\end{array}$ & $\begin{array}{c}\text { Events } \\
\text { expected }\end{array}$ \\
\hline Std. FT & 208 & 276.93 \\
Interrupted & 87 & 70.55 \\
Inactive & 61 & 32.43 \\
Self-empl. & 68 & 44.10 \\
\hline Total & & 424 & 424 \\
& & & \\
& chi2(2) & 68.33 \\
& Pr>chi2 & 0.000
\end{tabular}

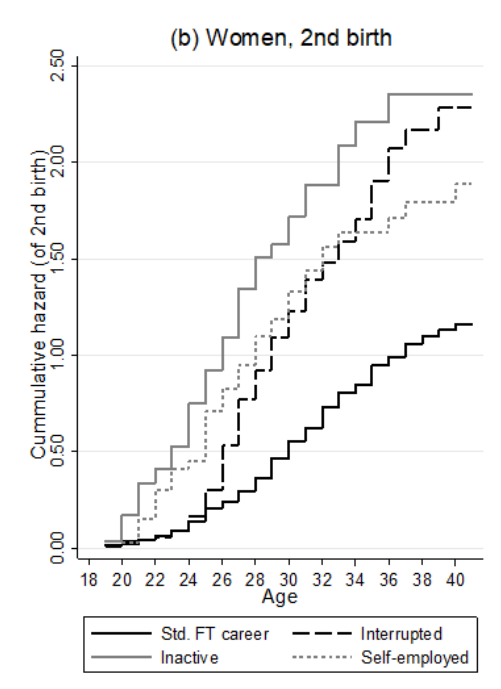

Log-rank test for equality of survivor functions

\begin{tabular}{l|l|c} 
& \multicolumn{1}{|c}{$\begin{array}{c}\text { Events } \\
\text { observed }\end{array}$} & $\begin{array}{c}\text { Events } \\
\text { expected }\end{array}$ \\
\hline Std. FT career & Std. FT & $\begin{array}{c}255.02 \\
\text { Interrupted }\end{array}$ \\
Inactive & Interruptive & 67.69 \\
Self employment & Inactive & 35.10 \\
& Self-empl. & 45.19 \\
\hline & Total & 403 \\
& & \\
& chi2(2) & 90.69 \\
& Pr>chi2 & 0.000
\end{tabular}

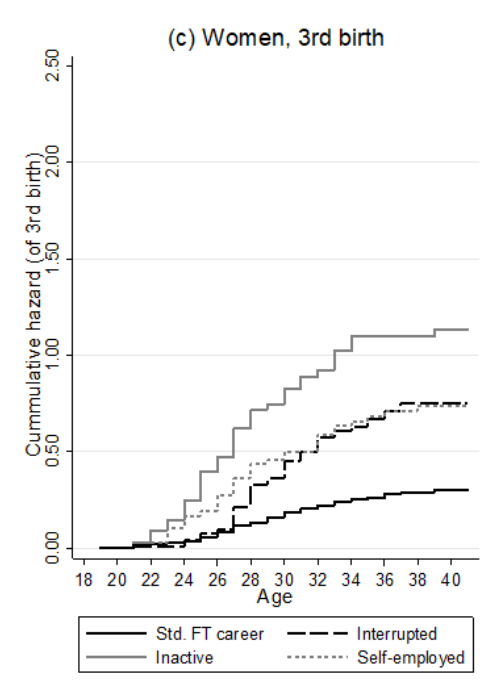

Log-rank test for equality of survivor functions

\begin{tabular}{l|cc} 
& $\begin{array}{c}\text { Events } \\
\text { observed }\end{array}$ & $\begin{array}{c}\text { Events } \\
\text { expected }\end{array}$ \\
\hline Std. FT & 66 & 120.83 \\
Interrupted & 52 & 39.84 \\
Inactive & 55 & 24.07 \\
Self-empl. & 41 & 29.26 \\
\hline Total & 214 & 214 \\
& & \\
& chi2(2) & 76.44 \\
& Pr>chi2 & 0.000
\end{tabular}


Additional analyses in Figures 2-b and 2-c show that the gap between inactive and standard full-time women in childbirth timing extends beyond the first birth. Inactive women lead women of all career groups in the second and the third birth transitions, while standard fulltime women constantly lag behind. The pace to second birth is similar between inactive and selfemployed women in early ages. However, the second-birth transition hazard has flattened among self-employed women after age 30, which has enlarged the cumulative hazard gap between selfemployed and inactive women by age 40. Similar patterns of career differentials in the pace of transition are also observed regarding women's third birth.

Figure 3: Nelson-Aalen cumulative hazard estimates and log-rank tests of group differences across men's career types by birth transitions.

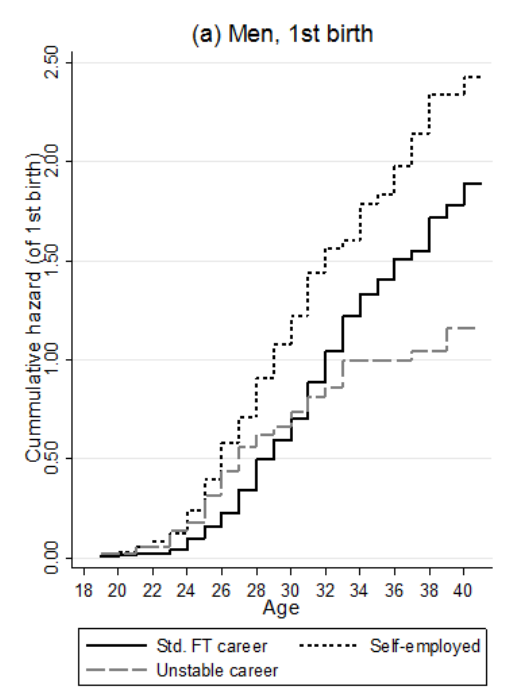

Log-rank test for equality of survivor functions

\begin{tabular}{l|cc} 
& $\begin{array}{c}\text { Events } \\
\text { observed }\end{array}$ & $\begin{array}{c}\text { Events } \\
\text { expected }\end{array}$ \\
\hline Std. FT & 327 & 355.73 \\
Self-empl. & 143 & 100.47 \\
Unstable & 38 & 51.79 \\
\hline Total & 508 & 508 \\
& & \\
& chi2(2) & 27.03 \\
& Pr>chi2 & 0.000
\end{tabular}

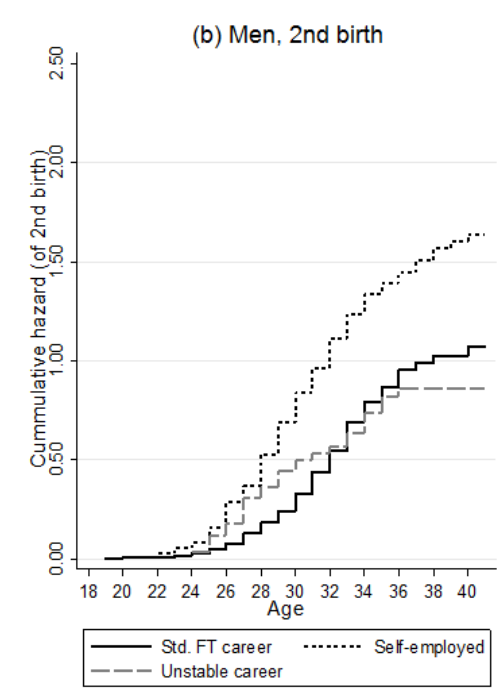

Log-rank test for equality of survivor functions

\begin{tabular}{l|cc} 
& $\begin{array}{c}\text { Events } \\
\text { observed }\end{array}$ & $\begin{array}{c}\text { Events } \\
\text { expected }\end{array}$ \\
\hline Std. FT & 254 & 293 \\
Self-empl. & 127 & 81.05 \\
Unstable & 32 & 38.96 \\
\hline Total & 413 & 413 \\
& & \\
& chi2(2) & 35.38 \\
& Pr>chi2 & 0.000
\end{tabular}

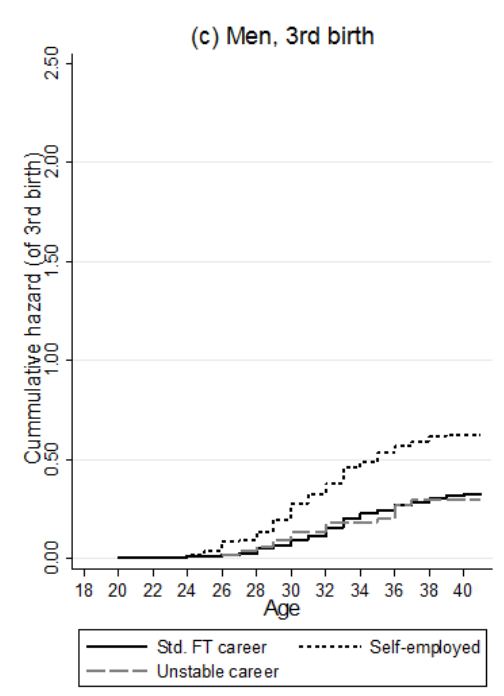

Log-rank test for equality of survivor functions

\begin{tabular}{l|cc} 
& $\begin{array}{c}\text { Events } \\
\text { observed }\end{array}$ & $\begin{array}{c}\text { Events } \\
\text { expected }\end{array}$ \\
\hline Std. FT & 105 & 129.4 \\
Self-empl. & 73 & 44.16 \\
Unstable & 14 & 18.44 \\
\hline Total & 192 & 192 \\
& & \\
& chi2(2) & 25.26 \\
& Pr>chi2 & 0.000
\end{tabular}


Figure 3 presents men's cumulative transition hazards to each birth, estimated by the Nelson-Aalen method. Figure 3-a indicates large career differentials in men's timing of fatherhood transition. Against my expectation in Hypothesis 2a, men with stable full-time careers have lower hazards of fatherhood before age 30 than men with unstable careers, indicating that standard full-time men are associated with a slightly slower fatherhood transition in early ages. This could be a result due to the longer time spent on tertiary education for these full-time employed men, which prevents them from early-age family formation (Buchmann \& Kriesi, 2011). However, full-time employed men catch up with and surpass unstable-career men in their pace to fatherhood after age 30. Eventually, a much lower cumulative hazard of fatherhood by age 40 has been observed for the latter group. Results in Figure 3-a also show that self-employed men have higher hazards of fatherhood transition comparing to standard full-time men, and that the gap between these two groups has already emerged in their early career lives. This finding supports Hypothesis 4a, indicating that self-employed men are associated with faster fatherhood transition in Taiwan.

Additional analyses in Figures 3-b and 3-c show that the career gaps of transition hazards among men extend beyond the fatherhood transition. Again, self-employed men lead all male groups in terms of the pace to the second and the third births. The cumulative hazards have converged between standard full-time men and unstable-career men in the third birth. Given the results in Figure 3a, these additional findings hint that the fertility deficit for unstable-career men might primarily reflect their difficulty of fatherhood transition after age 30 .

\section{Employment careers and fertility quantum}

Finally, I use multivariate regressions to adjust for group differences in socio-demographic characteristics (i.e., the confounding effects) to estimate the associations between career types 
and numbers of children by age 40 . Table 3 presents the average marginal effects (AMEs) of employment careers based on the Poisson regressions for women and men. Model 1 shows that women being economically inactive associates with 0.771 more children $(S . E .=0.128, p<.001)$ compared to being standard full-time employed. This result supports Hypothesis 1b, suggesting that women of unstable employment careers associate with a larger family size than women of stable careers. Self-employed women, compared to full-time career women, associate with 0.428 more children $(S . E .=0.140, p=.002)$. This finding supports Hypothesis $3 b$, suggesting that working as a self-employee may allow female workers in Taiwan to have more children.

Table 3: Poisson regression models of the number of children for women and men by age 40

\begin{tabular}{|c|c|c|c|c|c|c|c|}
\hline \multirow[b]{3}{*}{ Women's careers } & \multicolumn{3}{|c|}{ Model 1} & \multirow[b]{3}{*}{ Men's career } & \multicolumn{3}{|c|}{ Model 2} \\
\hline & $A M E$ & S.E. & p-value & & $A M E$ & S.E. & p-value \\
\hline & & & & & & & \\
\hline Std. FT career & Ref. & & & Std. FT career & Ref. & & \\
\hline Interrupted & 0.407 & 0.115 & $<.001$ & Self-employed & 0.330 & 0.104 & $<.001$ \\
\hline Inactive & 0.771 & 0.128 & $<.001$ & Unstable career & -0.306 & 0.154 & .047 \\
\hline Self-employed & 0.428 & 0.140 & .002 & & & & \\
\hline Birth cohorts & & & & Birth cohorts & & & \\
\hline $1946-57$ & Ref. & & & $1946-57$ & Ref. & & \\
\hline $1958-67$ & -0.401 & 0.104 & $<.001$ & $1958-67$ & -0.620 & 0.114 & $<.001$ \\
\hline $1968-77$ & -1.036 & 0.120 & $<.001$ & $1968-77$ & -1.032 & 0.107 & $<.001$ \\
\hline $\begin{array}{l}\text { At least one parent has a } \\
\text { tertiary degree }\end{array}$ & -0.170 & 0.195 & .384 & $\begin{array}{l}\text { At least one parent has a } \\
\text { tertiary degree }\end{array}$ & -0.158 & 0.231 & .493 \\
\hline Ethnic minority & -0.186 & 0.160 & .246 & Ethnic minority & -0.031 & 0.224 & .888 \\
\hline $\begin{array}{l}\text { Family economic } \\
\text { background by age } 15\end{array}$ & -0.060 & 0.038 & .112 & $\begin{array}{l}\text { Family economic } \\
\quad \text { background by age } 15\end{array}$ & 0.001 & 0.037 & .978 \\
\hline$N$ of cases & 507 & & & & 585 & & \\
\hline
\end{tabular}

Notes: The table presents predictive average marginal effects (AMEs) from the Poisson regression models. Bootstrapped standard errors with 200 bootstrap repetitions are calculated. p-values are calculated from the twotailed Wald tests.

For men, having an unstable career associates with a decreased fertility by -0.306 children $(S . E .=0.154, p=.047)$ compared to having a stable full-time career. In contrary, having a self-employed career, compared to a standard full-time career, associates with an increased 
fertility by 0.330 children $($ S.E. $=0.104, p=<.001)$. Both findings on the relationship between men's careers and their number of children support Hypotheses $2 \mathrm{~b}$ and $4 \mathrm{~b}$.

\section{Additional analyses on model robustness and cohort heterogeneity}

In the Supplementary materials S2, I perform three additional analyses to supplement the main findings on the career-fertility quantum associations presented in Table 3 . The first analysis further controls for one's highest educational level by age 40 in the Poisson models to account for the confounding effect related to educational differences (see Table S2.1). The second analysis uses a set of logistic regressions to model the parity-specific probabilities by age 40 (see Figure S2.2). Different from Poisson regressions of birth counts, this analysis makes no assumption on the fertility outcome distributions and allows a closer look into the parity composition of the group-specific fertility quantum. Results from both analyses confirm Table 3's findings that having a stable employment career associates with lower fertility for women but higher fertility for men; and a self-employment career may enhance both women's and men's fertility in Taiwan. Finally, I include a set of interaction terms between career types and cohorts in the Poisson models to explore whether and how these career-fertility relationships change over time (see Figure S2.3). In summary, Taiwanese people's "fertility rankings" by career groups are relatively stable across cohorts, although the "fertility differentials" by career have changed over time. The positive association between interrupted careers and fertility increased for younger women; and the negative association between unstable careers and men's fertility enlarged.

\section{Conclusion and Discussion}

Research interest in how people's employment situations affect their family behaviors has been growing (Buhr and Huinink, 2014; Kreyenfeld et al., 2012), particularly in an era when 
Globalization meets Second Demographic Transition (Blossfeld and Mills, 2005; Mills and Blossfeld, 2013). In East Asia, increased female labor force participation and rising employment precarity for men have been linked to the significant postponement of parenthood and the remarkable reduction of fertility (Jones, 2007; McDonald, 2009; Piotrowski et al., 2018). The current study adds to these discussions by exploring the holistic associations between women's and men's career types and their timing and quantum of fertility in Taiwan.

Overall, my findings largely support the theoretical predictions on the gendered relationship between employment careers' stability and people's fertility behaviors in familistic countries (Hypotheses 1a, 1b, and 2b are fully supported; 2a is partially supported). For Taiwanese women, having a stable employment career in full-time positions relates to a delayed motherhood transition comparing to staying economically inactive before midlife. After adjusting for individual socio-demographic variations, women who have a standard full-time career are associated with a significantly lower fertility quantum by age 40 comparing to inactive women. For Taiwanese men, it is having an unstable career, not a stable full-time career, that depresses the fatherhood transition, parity progressions, and total fertility. While results in Figure 3 show that unstable-career men might have a faster fatherhood transition before age 30 comparing to men with standard full-time careers, this early vantage waned in men's later life courses. Eventually, having an unstable career associates with a decreased male fertility by 0.306 children comparing to having a standard full-time career.

Besides the sharp gender contrasts in fertility outcomes between women and men with the most stable and the most unstable careers, my findings highlight the third career pathway toward a high fertility life course in Taiwan for both genders - a self-employment career. As discussed in the theory section, previous research suggests that whether self-employment has a 
fertility-enhancing or -depressing effect depends largely on the degree of institutional supports to combine work with childcare and the resource-related plausibility of self-employment comparing to other career choices (Adsera, 2011a; Anthias and Mehta, 2003; Matysiak and Mynarska, 2020; Noseleit, 2014). In Taiwan, given the shortage of work-family reconciliation policies (Bumpass et al., 2009; Gauthier, 2016) and the superiority of self-employees in mobilizing family resources (Lu, 2001; Yu and Su, 2009), self-employed women and men not only have a faster pace in parenthood transitions (Hypotheses 3a and 4a) but also a larger number of children by midlife (Hypotheses $3 b$ and 4b) than their counterparts in a standard full-time firm employment track.

It is worth noticing that while the supplementary analysis in Figure S2.3 shows a relatively stable fertility ranking by careers in the sample, the fertility differentials by careers are changing especially among the recent cohorts. With parental leaves becoming more prevalent and childcare facilities largely expended since 2010 , it will be an interesting topic to examine whether institutional changes can alter the career-fertility associations in Taiwan.

Beyond these substantive conclusions, this study also highlights the methodological advantage of investigating the life-course associations between employment "careers" and fertility "histories" using holistic approaches. Rather than analyzing isolated employment states in cross-sectional settings, this study uses holistic employment sequences between ages 18 and 40 to capture the idea of stability or instability in one's employment career (Biemann et al., 2012; Ciganda, 2015; Devillanova et al., 2019; Fuller and Stecy-Hildebrandt, 2015; McVicar et al., 2019). It also better illustrates the heterogeneity of employment life courses by documenting multiple career tracks. More importantly, this study investigates how different careers are associated with multiple fertility outcomes (i.e., timings and quantum) across gender. Its results complement previous research's focus on only one specific fertility outcome in certain ages for 
either women or men. In summary, the current study contributes to the emergent methodological emphases on providing a "thick description" of gender-specific work-family life courses (Aisenbrey and Fasang, 2017). It introduces work-family researchers in Taiwan and East Asia with a novel design to examine the theoretical interplay between employment and fertility over the life course as "process outcomes" (Abbott, 2016).

Some limitations are acknowledged. First, while using the holistic sequences is more informative than using cross-sectional states in capturing the objective stability of employment careers, it is still possible that a seemingly stable career trajectory did not translate into people's subjective feeling of stability. Future studies can extend the research by exploring how people's perceived job insecurity (Glavin et al., 2020) or narrative to the future (Vignoli et al., 2020) affects their fertility intentions and behaviors. Second, due to the limited retrospective information in the TSCS data, my analysis cannot control for individual heterogeneities in subjective attitudes toward work and family decisions. These attitudinal differences, including career-family preferences (Vitali et al., 2009) or risk aversion attitudes (Schmitt, 2021), are potential factors moderating the employment-fertility relationship. Finally, readers should be aware that this study's approach is designed to test the theoretical predictions on fertility variations by career types (see the hypotheses section). As mentioned before, the theoretical relationship between employment and fertility is bi-directional (Matysiak and Vignoli, 2008), indicating that people's fertility is not only affected by but also affecting their careers. In this regard, the empirical approach applied in this study is not an optimal tool to tackle the causal effects of careers on fertility or vice versa because it cannot isolate the sequential order of causality. However, the empirical focus on how people's holistic careers associate with their fertility outcomes is justified from a life course perspective, given the fact that work-family 
trajectories are unfolding in a simultaneous institutionalization process (Huinink and Kohli,

2014; Krüger and Levy, 2001). The present study's in-depth investigation into the employment-

fertility associations brings valuable insights to examine whether the life-course work-fertility

relationships are converging between Taiwan and other low-gender-equity societies (McDonald, 2013), including other East-Asian countries and Southern-European countries.

\section{References}

Abbott, A. (2016). Processual sociology. University of Chicago Press.

Adsera, A. (2011a). Where are the babies? Labor market conditions and fertility in Europe. European Journal of Population / Revue Européenne de Démographie, 27(1), 1-32. https://doi.org/10.1007/s10680-010-9222-x

Adsera, A. (2011b). The interplay of employment uncertainty and education in explaining second births in Europe. Demographic Research, 25(16), 513-544. https://doi.org/10.4054/DemRes.2011.25.16

Aisenbrey, S., and Fasang, A. (2017). The interplay of work and family trajectories over the life course: Germany and the United States in comparison. American Journal of Sociology, 122(5), 1448-1484. https://doi.org/10.1086/691128

Aisenbrey, S., and Fasang, A. E. (2010). New life for old ideas: The "Second Wave" of sequence analysis bringing the "course" back into the life course: Sociological Methods and Research. https://doi.org/10.1177/0049124109357532

Alderotti, G., Vignoli, D., Baccini, M., and Matysiak, A. (2021). Employment instability and fertility in Europe: A meta-analysis. Demography, 9164737. https://doi.org/10.1215/00703370-9164737

Anthias, F., and Mehta, N. (2003). The intersection between gender, the family, and selfemployment: The family as resource. International Review of Sociology, 13. https://doi.org/10.1080/0390670032000087014

Auer, W., and Danzer, N. (2016). Fixed-term employment and fertility: Evidence from German micro data. CESifo Economic Studies, 62(4), 595-623. https://doi.org/10.1093/cesifo/ifv014

Becker, G. S. (1991). A Treatise on the Family. Harvard university press.

Begall, K., and Mills, M. C. (2013). The influence of educational field, occupation, and 
occupational sex segregation on fertility in the Netherlands. European Sociological Review, 29(4), 720-742. https://doi.org/10.1093/esr/jcs051

Bernardi, L., Huinink, J., and Settersten, R. A. (2019). The life course cube: A tool for studying lives. Advances in Life Course Research, 41, 100258. https://doi.org/10.1016/j.alcr.2018.11.004

Biemann, T., Zacher, H., and Feldman, D. C. (2012). Career patterns: A twenty-year panel study. Journal of Vocational Behavior, 81(2), 159-170. https://doi.org/10.1016/j.jvb.2012.06.003

Blossfeld, H.-P., and Mills, M. (2005). Globalization, uncertainty and the early life course: A theoretical framework. In Hans-Peter Blossfeld, Erik Klijzing, Melinda Mills, and Karin Kurz (Eds.), Globalization, uncertainty and youth in society. Routledge. https://fis.unibamberg.de/handle/uniba/13081

Brinton, M. C. (2001). Women's Working Lives in East Asia. Stanford University Press.

Brinton, M. C., and Oh, E. (2019). Babies, work, or both? Highly educated women's employment and fertility in East Asia. American Journal of Sociology, 125(1), 105-140. https://doi.org/10.1086/704369

Brzinsky-Fay, C. (2010). The concept of transitional labour markets: A theoretical and methodological inventory. WZB Discussion Paper, SP I 2010-507.

Buchmann, M. C., \& Kriesi, I. (2011). Transition to adulthood in Europe. Annual Review of Sociology, 37(1), 481-503. https://doi.org/10.1146/annurev-soc-081309-150212

Buhr, P., and Huinink, J. (2014). Fertility analysis from a life course perspective. Advances in Life Course Research, 21, 1-9. https://doi.org/10.1016/j.alcr.2014.04.001

Bumpass, L. L., Rindfuss, R. R., Choe, M. K., and Tsuya, N. O. (2009). The institutional context of low fertility. Asian Population Studies, 5(3), 215-235. https://doi.org/10.1080/17441730903351479

Busetta, A., Mendola, D., and Vignoli, D. (2019). Persistent joblessness and fertility intentions. Demographic Research, 40, 185-218.

Chen, S.-J., Ko, J.-J. R., and Lawler, J. (2003). Changing patterns of industrial relations in Taiwan. Industrial Relations: A Journal of Economy and Society, 42(3), 315-340. https://doi.org/10.1111/1468-232X.t01-1-00294

Cheng, Yen-hsin Alice, and Hsu, C.-H. (2020). No more babies without help for whom? Education, division of labor, and fertility intentions. Journal of Marriage and Family, 82(4), 1270-1285. https://doi.org/10.1111/jomf.12672

Cheng, Yen-hsin Alice. (2020). Ultra-low fertility in East Asia: Confucianism and its discontents. Vienna Yearbook of Population Research, 18, 1-38. 
https://doi.org/10.1553/populationyearbook2020.rev01

Ciganda, D. (2015). Unstable work histories and fertility in France: An adaptation of sequence complexity measures to employment trajectories. Demographic Research, 32(28), 843876. https://doi.org/10.4054/DemRes.2015.32.28

Del Boca, D., Pasqua, S., and Pronzato, C. (2005). Fertility and employment in Italy, France, and the UK. LABOUR, 19(s1), 51-77. https://doi.org/10.1111/j.1467-9914.2005.00323.x

Devillanova, C., Raitano, M., and Struffolino, E. (2019). Longitudinal employment trajectories and health in middle life: Insights from linked administrative and survey data. Demographic Research, 40, 1375-1412. https://doi.org/10.4054/DemRes.2019.40.47

Efron, B., and Tibshirani, R. (1986). Bootstrap methods for standard errors, confidence intervals, and other measures of statistical accuracy. Statistical Science, 1(1), 54-75. http://www.jstor.org/stable/2245500

Elder, G. H., Johnson, M. K., and Crosnoe, R. (2003). The emergence and development of life course theory. In J. T. Mortimer and M. J. Shanahan (Eds.), Handbook of the Life Course (pp. 3-19). Springer US. https://doi.org/10.1007/978-0-306-48247-2_1

Fauser, S. (2020). Career trajectories and cumulative wages: The case of temporary employment. Research in Social Stratification and Mobility, 69, 100529. https://doi.org/10.1016/j.rssm.2020.100529

Frejka, T., Jones, G. W., and Sardon, J.-P. (2010). East Asian childbearing patterns and policy developments. Population and Development Review, 36(3), 579-606. https://doi.org/10.1111/j.1728-4457.2010.00347.x

Friedman, D., Hechter, M., and Kanazawa, S. (1994). A theory of the value of children. Demography, 31(3), 375-401. https://doi.org/10.2307/2061749

Fu, Y.-C. (2019). 2017 Taiwan Social Change Survey (Round 7, Year 3): Social Stratification (C00339_1) [data file]. Available from the Survey Research Data Archive, Academia Sinica, Taiwan. doi:10.6141/TW-SRDA-C00339_1-3.

Fuller, S., and Stecy-Hildebrandt, N. (2015). Career pathways for temporary workers: Exploring heterogeneous mobility dynamics with sequence analysis. Social Science Research, 50, 76-99. https://doi.org/10.1016/j.ssresearch.2014.11.003

Gabadinho, A., Ritschard, G., Müller, N. S., and Studer, M. (2011). Analyzing and visualizing state sequences in $R$ with TraMineR. Journal of Statistical Software, 40(4). https://doi.org/10.18637/jss.v040.i04

Gauthier, A. H. (2016). Governmental support for families and obstacles to fertility in East Asia and other industrialized regions. In Low fertility, institutions, and their policies (pp. 283303). Springer. 
Gietel-Basten, S. (2019). The "Population Problem" in Pacific Asia. Oxford University Press.

Glavin, P., Young, M., and Schieman, S. (2020). Labor market influences on women's fertility decisions: Longitudinal evidence from Canada. Social Science Research, 88-89, 102417. https://doi.org/10.1016/j.ssresearch.2020.102417

Goldstein, J. R., Sobotka, T., and Jasilioniene, A. (2009). The end of "lowest-low" fertility? Population and Development Review, 35(4), 663-699. https://doi.org/10.1111/j.17284457.2009.00304.x

Guan, W. (2003). From the Help Desk: Bootstrapped standard errors. The Stata Journal, 3(1), 71-80. https://doi.org/10.1177/1536867X0300300105

Hakim, C. (2000). Work-lifestyle Choices in the 21st Century: Preference Theory. Oxford University Press.

Hilgeman, C., and Butts, C. T. (2009). Women's employment and fertility: A welfare regime paradox. Social Science Research, 38(1), 103-117. https://doi.org/10.1016/j.ssresearch.2008.08.005

Hsiao, H.-H. M. (2013). Precarious work in Taiwan: A profile. American Behavioral Scientist, 57(3), 373-389. https://doi.org/10.1177/0002764212466243

Hsiao, H.-H. M., Kalleberg, A. L., and Hewison, K. (2015). Policy Responses to Precarious Work in Asia. Institute of Sociology, Academia Sinica.

Huinink, J., and Feldhaus, M. (2009). Family research from the life course perspective. International Sociology, 24(3), 299-324. https://doi.org/10.1177/0268580909102910

Huinink, J., and Kohli, M. (2014). A life-course approach to fertility. Demographic Research, 30, 1293-1326. https://doi.org/10.4054/DemRes.2014.30.45

Jones, G. W. (2007). Delayed marriage and very low fertility in Pacific Asia. Population and Development Review, 33(3), 453-478. https://doi.org/10.1111/j.1728-4457.2007.00180.x

Jones, G. W. (2019). Ultra-low fertility in East Asia: Policy responses and challenges. Asian Population Studies, 15(2), 131-149. https://doi.org/10.1080/17441730.2019.1594656

Kalleberg, A. L. (2009). Precarious work, insecure workers: Employment relations in transition. American Sociological Review, 74(1), 1-22. https://doi.org/10.1177/000312240907400101

Kalleberg, A. L., and Hewison, K. (2013). Precarious work and the challenge for Asia. American Behavioral Scientist, 57(3), 271-288. https://doi.org/10.1177/0002764212466238

Kaufman, L., \& Rousseeuw, P. J. (2009). Finding groups in data: An introduction to cluster analysis (Vol. 344). John Wiley \& Sons. 
Keizer, R., Dykstra, P. A., and Jansen, M. D. (2008). Pathways into childlessness: Evidence of gendered life course dynamics. Journal of Biosocial Science, 40(6), 863-878. https://doi.org/10.1017/S0021932007002660

Köppen, K., Mazuy, M., and Toulemon, L. (2017). Childlessness in France. In Childlessness in Europe: Contexts, causes, and consequences (pp. 77-95). Springer, Cham.

Kreyenfeld, M. (2010). Uncertainties in female employment careers and the postponement of parenthood in Germany. European Sociological Review, 26(3), 351-366. https://doi.org/10.1093/esr/jcp026

Kreyenfeld, M., Andersson, G., and Pailhé, A. (2012). Economic uncertainty and family dynamics in Europe: Introduction. Demographic Research, 27, 835-852.

Krüger, H., and Levy, R. (2001). Linking Life Courses, Work, and the family: Theorizing a not so visible nexus between women and men. The Canadian Journal of Sociology / Cahiers Canadiens de Sociologie, 26(2), 145-166. https://doi.org/10.2307/3341676

Lu, Y.-H. (2001). Gender, family and economy: Status as the "Boss's Wife" in small Taiwanese family businesses. Taiwanese Sociology, 2, 163-217. https://doi.org/10.6676/TS.2001.2.163

Matysiak, A. (2011). Interdependencies between fertility and women's labour supply (Vol. 17). Springer Science \& Business Media.

Matysiak, A., and Mynarska, M. (2020). Self-employment as a work-and-family reconciliation strategy? Evidence from Poland. Advances in Life Course Research, 45, 100329. https://doi.org/10.1016/j.alcr.2020.100329

Matysiak, A., and Vignoli, D. (2008). Fertility and women's employment: A meta-analysis [Fécondité et travail des femmes: une méta-analyse]. European Journal of Population / Revue Européenne de Démographie, 24(4), 363-384. https://doi.org/10.1007/s10680007-9146-2

Matysiak, A., and Vignoli, D. (2013). Diverse effects of women's employment on fertility: Insights from Italy and Poland [Diverses conséquences de l'emploi des femmes sur la fécondité: quelques informations à partir des cas de l'Italie et de la Pologne]. European Journal of Population / Revue Européenne de Démographie, 29(3), 273-302. https://doi.org/10.1007/s10680-013-9287-4

Mayer, K. U. (2009). New directions in life course research. Annual Review of Sociology, 35(1), 413-433. https://doi.org/10.1146/annurev.soc.34.040507.134619

McDonald, P. (2009). Explanations of low fertility in East Asia: A comparative perspective. In Ultra-low fertility in Pacific Asia: Trends, causes and policy issues. Routledge, Taylor \& Francis Group.

McDonald, P. (2013). Societal foundations for explaining low fertility: Gender equity. 
Demographic Research, 28, 981-994.

McVicar, D., Wooden, M., Laß, I., and Fok, Y.-K. (2019). Contingent employment and labour market pathways: Bridge or trap? European Sociological Review, 35(1), 98-115. https://doi.org/10.1093/esr/jcy045

Mills, M. (2010). Introducing survival and event history analysis. SAGE Publications Ltd.

Mills, M., and Blossfeld, H.-P. (2013). The Second Demographic Transition meets Globalization: A comprehensive theory to understand changes in family formation in an era of rising uncertainty. In A. Evans and J. Baxter (Eds.), Negotiating the Life Course: Stability and Change in Life Pathways (pp. 9-33). Springer Netherlands. https://doi.org/10.1007/978-90-481-8912-0_2

Ministry of Education. (2020). Number of kindergarten and number of children registered in kindergarten [幼兒園園數及幼兒園幼生數(性別)]. Ministry of Education.

Ministry of Health and Welfare. (2020). Number of organizations and cared cases [托嬰中心所 數及收托人數]. Ministry of Health and Welfare. https://dep.mohw.gov.tw/DOS/cp2978-13971-113.html

Ministry of Labour. (2020). Number of male and female recipients of parental leave childcare benefits [育嬰留職停薪津貼核付情形]. Ministry of Labour.

https://statdb.mol.gov.tw/statis/jspProxy.aspx?sys=210\&kind=21\&type=1\&funid=q0605 $2 \& \mathrm{rdm}=\mathrm{K} 6 \mathrm{pxelci}$

Mynarska, M., Matysiak, A., Rybińska, A., Tocchioni, V., and Vignoli, D. (2015). Diverse paths into childlessness over the life course. Advances in Life Course Research, 25, 35-48. https://doi.org/10.1016/j.alcr.2015.05.003

Nauck, B., Gröpler, N., and Yi, C.-C. (2017). How kinship systems and welfare regimes shape leaving home: A comparative study of the United States, Germany, Taiwan, and China. Demographic Research, 36(38), 1109-1148. https://doi.org/10.4054/DemRes.2017.36.38

Noseleit, F. (2014). Female self-employment and children. Small Business Economics, 43(3), 549-569. https://doi.org/10.1007/s11187-014-9570-8

Oppenheimer, V. K. (1988). A theory of marriage timing. American Journal of Sociology, 94(3), 563-591. https://doi.org/10.1086/229030

Oppenheimer, V. K., Kalmijn, M., and Lim, N. (1997). Men's career development and marriage timing during a period of rising inequality. Demography, 34(3), 311-330. https://doi.org/10.2307/3038286

Özcan, B., Mayer, K. U., and Luedicke, J. (2010). The impact of unemploument on the transition to parenthood. Demographic Research, 23, 807-846.

Pailhé, A., and Solaz, A. (2012). The influence of employment uncertainty on childbearing in 
France: A tempo or quantum effect? Demographic Research, 26, 1-40.

Tsai, P.-Y. (2012). The transformation of leave policies for work-family balance in Taiwan. Asian Women, 28(2), 27-54.

Piccarreta, R., \& Struffolino, E. (2019). An integrated heuristic for validation in sequence analysis. Preprint in SocArXiv. https://doi.org/10.31235/osf.io/v7mj8

Piotrowski, M., Kalleberg, A., Bond, E., and Wolford, R. (2018). Non-standard work and fertility: A comparison of the US and Japan. Asian Population Studies, 14(2), 116-136. https://doi.org/10.1080/17441730.2018.1446310

Pollock, G. (2007). Holistic trajectories: A study of combined employment, housing and family careers by using multiple-sequence analysis. Journal of the Royal Statistical Society: Series A (Statistics in Society), 170(1), 167-183. https://doi.org/10.1111/j.1467985X.2006.00450.x

Raymo, J. M., and Shibata, A. (2017). Unemployment, nonstandard employment, and fertility: Insights from Japan's “Lost 20 Years.” Demography, 54(6), 2301-2329. https://doi.org/10.1007/s13524-017-0614-y

Raymo, J. M., Park, H., Xie, Y., and Yeung, W. J. (2015). Marriage and family in East Asia: Continuity and change. Annual Review of Sociology, 41(1), 471-492. https://doi.org/10.1146/annurev-soc-073014-112428

Reichenberg, O., and Berglund, T. (2019). "Stepping up or stepping down?": The earnings differences associated with Swedish temporary workers' employment sequences. Social Science Research, 82, 126-136. https://doi.org/10.1016/j.ssresearch.2019.04.007

Schmitt, C. (2021). The impact of economic uncertainty, precarious employment, and risk attitudes on the transition to parenthood. Advances in Life Course Research, 47, 100402. https://doi.org/10.1016/j.alcr.2021.100402

Simonson, J., Gordo, L. R., and Titova, N. (2011). Changing employment patterns of women in Germany: How do baby boomers differ from older cohorts? A comparison using sequence analysis. Advances in Life Course Research, 16(2), 65-82. https://doi.org/10.1016/j.alcr.2011.03.002

Sinyavskaya, O., and Billingsley, S. (2015). The importance of job characteristics to women's fertility intentions and behavior in Russia. Genus, 71(1), 23-59. https://www.jstor.org/stable/genus.71.1.23

Sirniö, O., Kauppinen, T. M., and Martikainen, P. (2017). Intergenerational determinants of joint labor market and family formation pathways in early adulthood. Advances in Life Course Research, 34, 10-21. https://doi.org/10.1016/j.alcr.2017.09.001

Speare Jr., A., Speare, M. C., and Lin, H.-S. (1973). Urbanization, non-familial work, education, and fertility in Taiwan. Population Studies, 27(2), 323-334. 
https://doi.org/10.1080/00324728.1973.10405713

Stokes, C. S., and Hsieh, Y.-S. (1983). Female employment and reproductive behavior in Taiwan, 1980. Demography, 20(3), 313. https://doi.org/10.2307/2061245

Studer, M. (2013). WeightedCluster library manual: A practical guide to creating typologies of trajectories in the social sciences with R. LIVES Working Papers, 24, 1-32. https://doi.org/10.12682/lives.2296-1658.2013.24

Studer, M., and Ritschard, G. (2016). What matters in differences between life trajectories: A comparative review of sequence dissimilarity measures. Journal of the Royal Statistical Society. Series A (Statistics in Society), 481-511. https://doi.org/10.1111/rssa.12125

Tocchioni, V. (2018). Exploring the childless universe: Profiles of women and men without children in Italy. Demographic Research, 38, 451-470. https://www.jstor.org/stable/26457053

Vignoli, D., Bazzani, G., Guetto, R., Minello, A., and Pirani, E. (2020). Uncertainty and narratives of the future: A theoretical framework for contemporary fertility. In R. Schoen (Ed.), Analyzing Contemporary Fertility (Vol. 51, pp. 25-47). Springer International Publishing. https://doi.org/10.1007/978-3-030-48519-1_3

Vignoli, D., Tocchioni, V., and Salvini, S. (2016). Uncertain lives: Insights into the role of job precariousness in union formation in Italy. Demographic Research, 35(10), 253-282. https://doi.org/10.4054/DemRes.2016.35.10

Vitali, A., Billari, F. C., Prskawetz, A., and Testa, M. R. (2009). Preference theory and low fertility: A comparative perspective. European Journal of Population / Revue Européenne de Démographie, 25(4), 413-438. https://doi.org/10.1007/s10680-009-9178$\mathrm{X}$

Wu, H., and Chuang, H.-L. (2018). An empirical analysis of the impact of employment on the first birth decision for married women in Taiwan. In Advances in Pacific Basin Business, Economics and Finance (Vol. 6, pp. 249-276). Emerald Publishing Limited. https://doi.org/10.1108/S2514-465020180000006008

Yeung, W. J., and Alipio, C. (2013). Introduction: Transitioning to adulthood in Asia: School, work, and family life. The Annals of the American Academy of Political and Social Science, 646, 6-27. JSTOR. https://doi.org/10.2307/23479234

Yu, W. (2009). Gendered trajectories: Women, work, and social change in Japan and Taiwan. Stanford University Press.

Yu, W., and Su, K.-H. (2009). On one's own: Self-employment activity in Taiwan. The Reemergence of Self-Employment: A Comparative Study of Self-Employment Dynamics and Social Inequality. 


\section{[Appendix]}

Table A1: Descriptive statistics of variables in each subsample.

\begin{tabular}{|c|c|c|c|c|}
\hline & \multicolumn{2}{|c|}{ Female sample } & \multicolumn{2}{|c|}{ Male sample } \\
\hline & Mean; \% & Std. Dev. & Mean; \% & Std. Dev. \\
\hline \multicolumn{5}{|l|}{ Fertility variables } \\
\hline \multicolumn{5}{|l|}{ Age at birth (given a birth event) } \\
\hline Age at 1st birth & 24.98 & 4.58 & 28.77 & 4.41 \\
\hline Age at 2 nd birth & 27.20 & 4.91 & 30.59 & 4.40 \\
\hline Age at 3rd birth & 28.33 & 4.56 & 32.32 & 4.73 \\
\hline Number of children by age 40 & 2.27 & 1.18 & 2.05 & 1.16 \\
\hline \multicolumn{5}{|l|}{ Control variables } \\
\hline \multicolumn{5}{|l|}{ Individual's birth cohort } \\
\hline $1946-57$ & 32.94 & & 31.11 & \\
\hline $1958-67$ & 35.11 & & 37.61 & \\
\hline 1968-77 & 31.95 & & 31.28 & \\
\hline \multicolumn{5}{|l|}{ Parental education } \\
\hline Both parents have non-tertiary educ & 94.28 & & 94.02 & \\
\hline At least one parent has tertiary educ & 5.72 & & 5.98 & \\
\hline \multicolumn{5}{|l|}{ Ethnic minority } \\
\hline No & 89.35 & & 90.94 & \\
\hline Yes & 10.65 & & 9.06 & \\
\hline $\begin{array}{l}\text { Family economic background by age } 15 \text { (1- } \\
\text { scale) }\end{array}$ & 2.84 & 1.11 & 2.80 & 1.09 \\
\hline \multicolumn{5}{|c|}{ Individual's highest educational level by age 40} \\
\hline Primary & 42.41 & & 33.16 & \\
\hline Secondary & 42.21 & & 49.06 & \\
\hline Tertiary & 15.38 & & 17.78 & \\
\hline Number of cases & 507 & & 585 & \\
\hline Number of observations (person-years) & 11,661 & & 13,455 & \\
\hline
\end{tabular}


Table A2: Selective comparisons of average Silhouette widths (ASWs) across different clustering methods.

\begin{tabular}{|c|c|c|c|c|c|c|c|}
\hline \multirow{2}{*}{$\begin{array}{l}\text { Algorithm for } \\
\text { calculating sequence } \\
\text { distances matrix }\end{array}$} & \multirow{2}{*}{$\begin{array}{l}\text { Clustering } \\
\text { procedure }\end{array}$} & \multicolumn{3}{|c|}{ Clustering solution for women } & \multicolumn{3}{|c|}{ Clustering solution for men } \\
\hline & & $\begin{array}{l}\mathrm{N} \text { of } \\
\text { clusters }\end{array}$ & ASW & $\begin{array}{l}\text { Cluster-specific } \\
\text { ASW }\end{array}$ & $\begin{array}{l}\mathrm{N} \text { of } \\
\text { clusters }\end{array}$ & ASW & $\begin{array}{l}\text { Cluster-specific } \\
\text { ASW }\end{array}$ \\
\hline OMspell & Ward & 4 & 0.38 & $\begin{array}{l}0.61 ; 0.30 \\
-0.02 ; 0.62\end{array}$ & 3 & 0.49 & $0.55 ; 0.45 ; 0.21$ \\
\hline HAM & Ward & 4 & 0.40 & $\begin{array}{l}0.54 ;-0.12 \\
0.47 ; 0.59\end{array}$ & 3 & 0.54 & $0.57 ; 0.59 ; 0.21$ \\
\hline OMspell & PAM+Ward & 4 & 0.41 & $\begin{array}{l}0.53 ; 0.48 ; \\
0.11 ; 0.42\end{array}$ & 5 & 0.38 & $\begin{array}{l}0.43 ; 0.45 ; 0.48 ; \\
0.47 ; 0.26\end{array}$ \\
\hline HAM & PAM+Ward & 4 & 0.42 & $\begin{array}{l}0.48 ; 0.33 ; \\
0.52 ; 0.19\end{array}$ & 3 & 0.57 & $0.63 ; 0.53 ; 0.27$ \\
\hline
\end{tabular}

Note: The Silhouette width is a measure commonly used to evaluate the clustering quality. It compares the average distance of a sequence to sequences in its cluster with the average distance to the sequences in the closest clusters in a Euclidian space. At the global level, a higher average Silhouette width (ASW) for a clustering solution denotes a better clustering quality due to the averagely higher within-cluster homogeneity across subclusters. We can also use the clusterspecific ASWs to evaluate the closeness of sequences in each cluster. According to Table A2, the clustering results using the PAM+Ward method generally render a better global-level ASW. Both using the HAM algorithm for distance calculation, the PAM+Ward procedure outperforms the Ward procedure by scoring higher global-level ASWs for both genders. More importantly, women's results using the HAM with PAM+Ward method makes sure that every subclusters are appropriately specified by avoiding a negative ASW observed in one of the clusters in the HAM with Ward procedure (i.e., the subcluster with an ASW of -0.12). 
Table A3: Poisson regression models of the number of children for women and men by age 40, conditioning on educational level by age 40 .

\begin{tabular}{|c|c|c|c|c|c|c|c|}
\hline \multirow[b]{3}{*}{ Women's careers } & \multicolumn{3}{|c|}{ Model 1} & \multirow[b]{3}{*}{ Men's career } & \multicolumn{3}{|c|}{ Model 2} \\
\hline & $A M E$ & S.E. & p-value & & $A M E$ & S.E. & p-value \\
\hline & & & & & & & \\
\hline Std. FT career & Ref. & & & Std. FT career & Ref. & & \\
\hline Interrupted & 0.251 & 0.121 & .038 & Self-employed & 0.270 & 0.103 & .009 \\
\hline Inactive & 0.577 & 0.147 & $<.001$ & Unstable career & -0.381 & 0.179 & .034 \\
\hline Self-employed & 0.241 & 0.135 & .074 & & & & \\
\hline Birth cohorts & & & & Birth cohorts & & & \\
\hline $1946-57$ & Ref. & & & $1946-57$ & Ref. & & \\
\hline $1958-67$ & -0.315 & 0.105 & .003 & $1958-67$ & -0.539 & 0.103 & $<.001$ \\
\hline $1968-77$ & -0.847 & 0.137 & $<.001$ & $1968-77$ & -0.918 & 0.122 & $<.001$ \\
\hline $\begin{array}{l}\text { At least one parent has a } \\
\text { tertiary degree }\end{array}$ & 0.027 & 0.218 & .903 & $\begin{array}{l}\text { At least one parent has a } \\
\text { tertiary degree }\end{array}$ & -0.097 & 0.218 & .656 \\
\hline Ethnic minority & -0.220 & 0.150 & .144 & Ethnic minority & -0.017 & 0.209 & .936 \\
\hline $\begin{array}{l}\text { Family economic } \\
\text { background by age } 15\end{array}$ & -0.016 & 0.042 & .694 & $\begin{array}{l}\text { Family economic } \\
\text { background by age } 15\end{array}$ & 0.031 & 0.044 & .487 \\
\hline Educational level & & & & Educational level & & & \\
\hline Primary & Ref. & & & Primary & Ref. & & \\
\hline Secondary & -0.407 & 0.099 & $<.001$ & Secondary & -0.222 & 0.105 & .034 \\
\hline Tertiary & -0.729 & 0.156 & $<.001$ & Tertiary & -0.365 & 0.141 & .010 \\
\hline Observation & 507 & & & & 585 & & \\
\hline
\end{tabular}

Note: The table presents predictive average marginal effects (AMEs) from the Poisson regression models.

Bootstrapped standard errors with 200 bootstrap repetitions are calculated. p-values are calculated from the twotailed Wald tests. 
Figure A1: Partitioning quality indicators by clustering solutions.

(a) Women
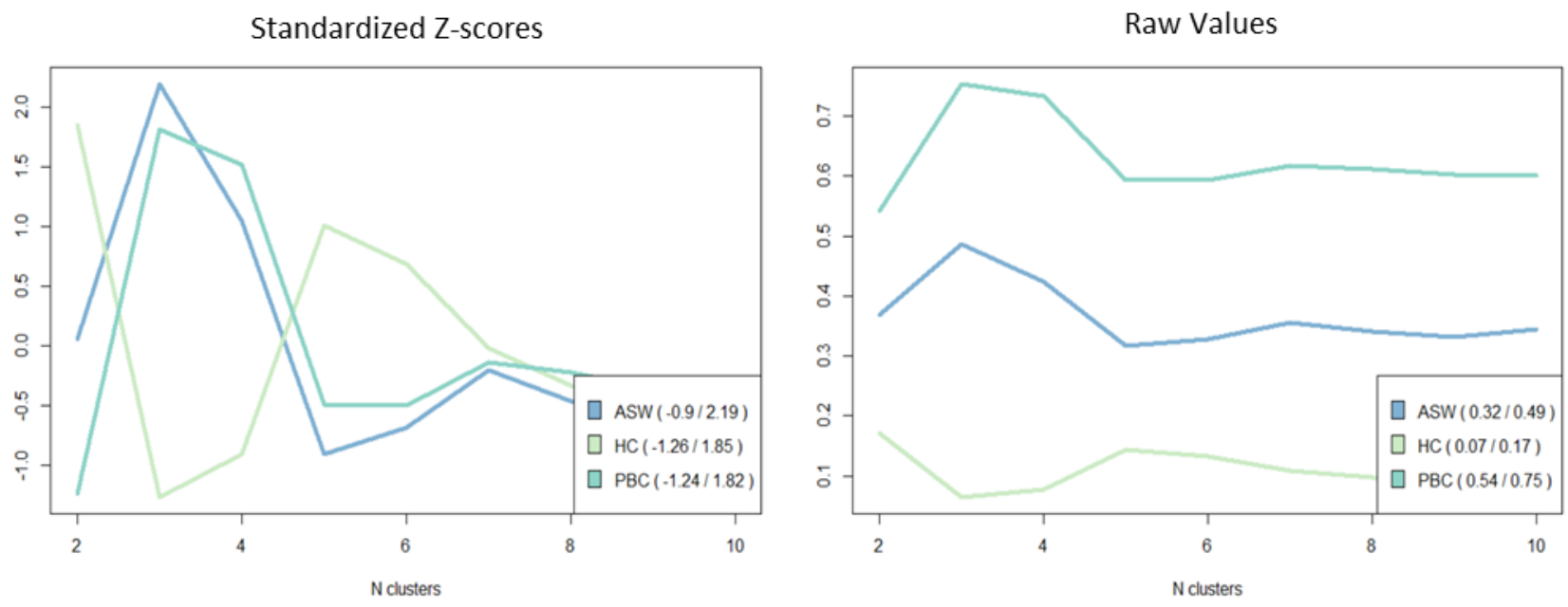

\section{(b) Men}
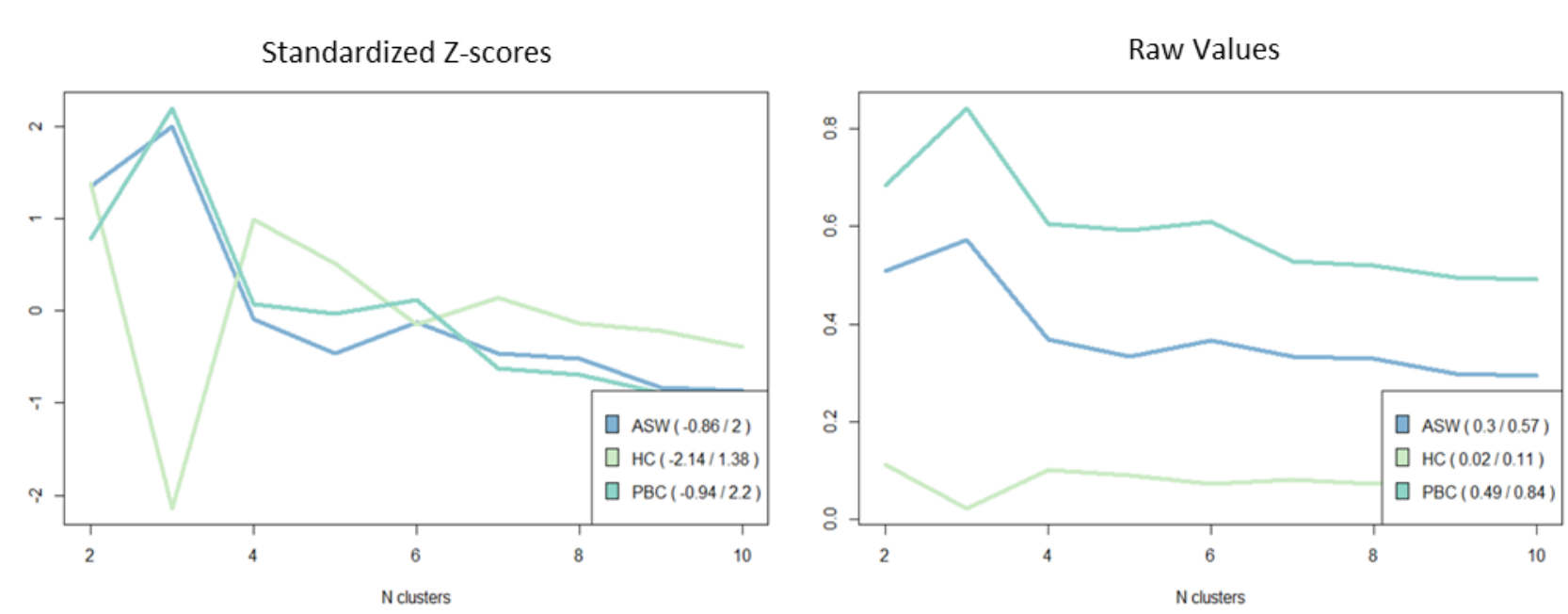

Note: Using the PAM+Ward procedure for clustering, this study's method aims to allocate each sequence to their closest medoid. In this context, the higher the average Silhouette width (ASW), higher the intra-cluster closeness between sequences. Similarly, the higher the point biserial correlation (PBC), the closer the sequences within a cluster. The interpretation of the Hubert's C (HC) is from the opposite direction: the lower the HC, the better the intra-cluster closeness. For women. all three indicators indicate 3 clusters as the best solution, with 4 clusters being the second best in a close margin. After evaluating the substantive meaningfulness of clusters, I opt for the 4-cluster solution because rather than pooling all women with relatively long non-employment duration into one large group, the 4-cluster solution makes a theoretically meaningful distinction between the long-term "inactive career" and the "interrupted career." For men, all three indicators indicate 3 clusters as optimal. 
Figure A2: Silhouette widths by cluster for women's four-cluster solution.

\section{Silhouette by cluster group, women}

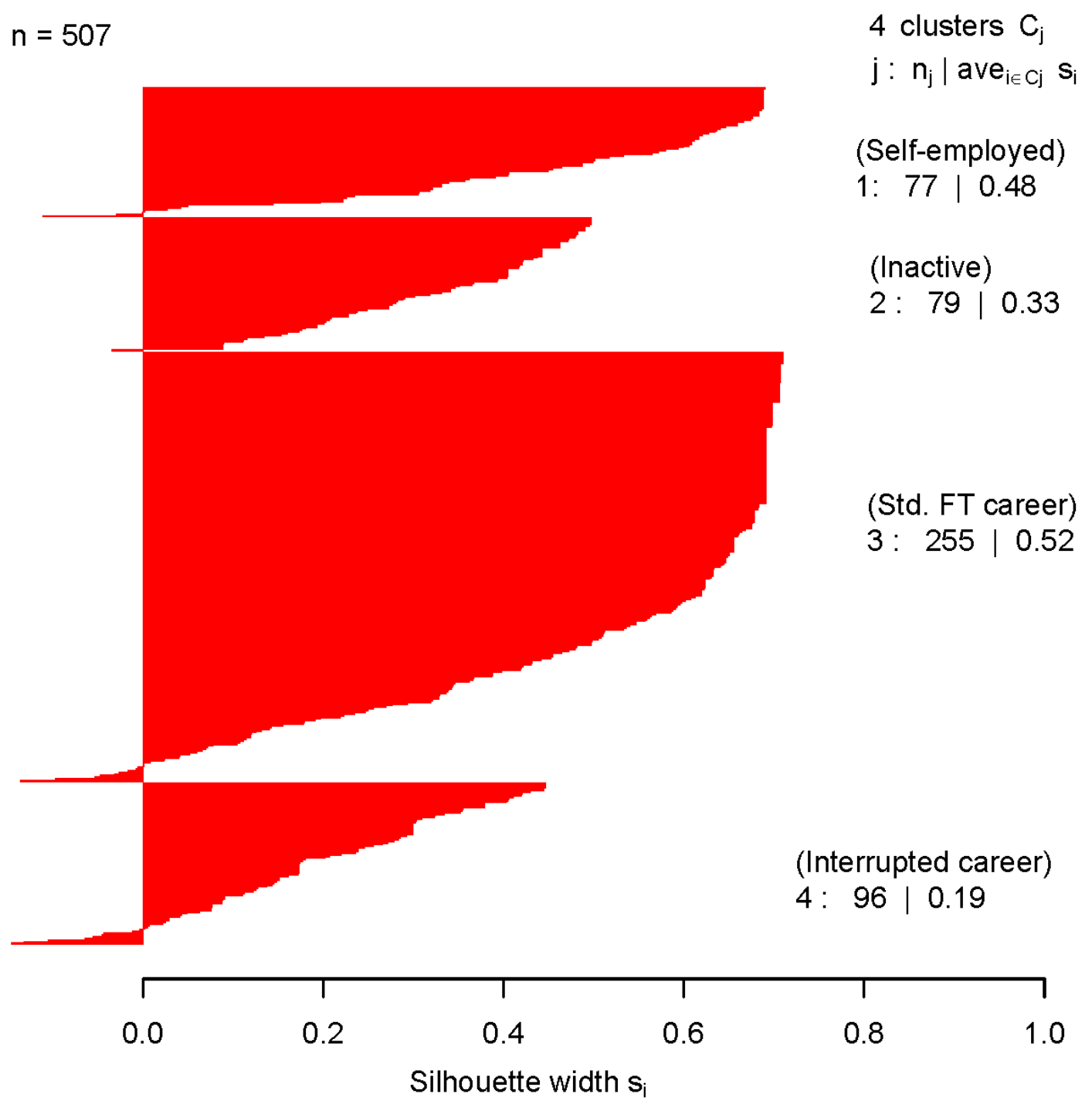

Average silhouette width : 0.42 
Figure A3: Silhouette widths by cluster for men's three-cluster solution.

Silhouette by cluster group, men

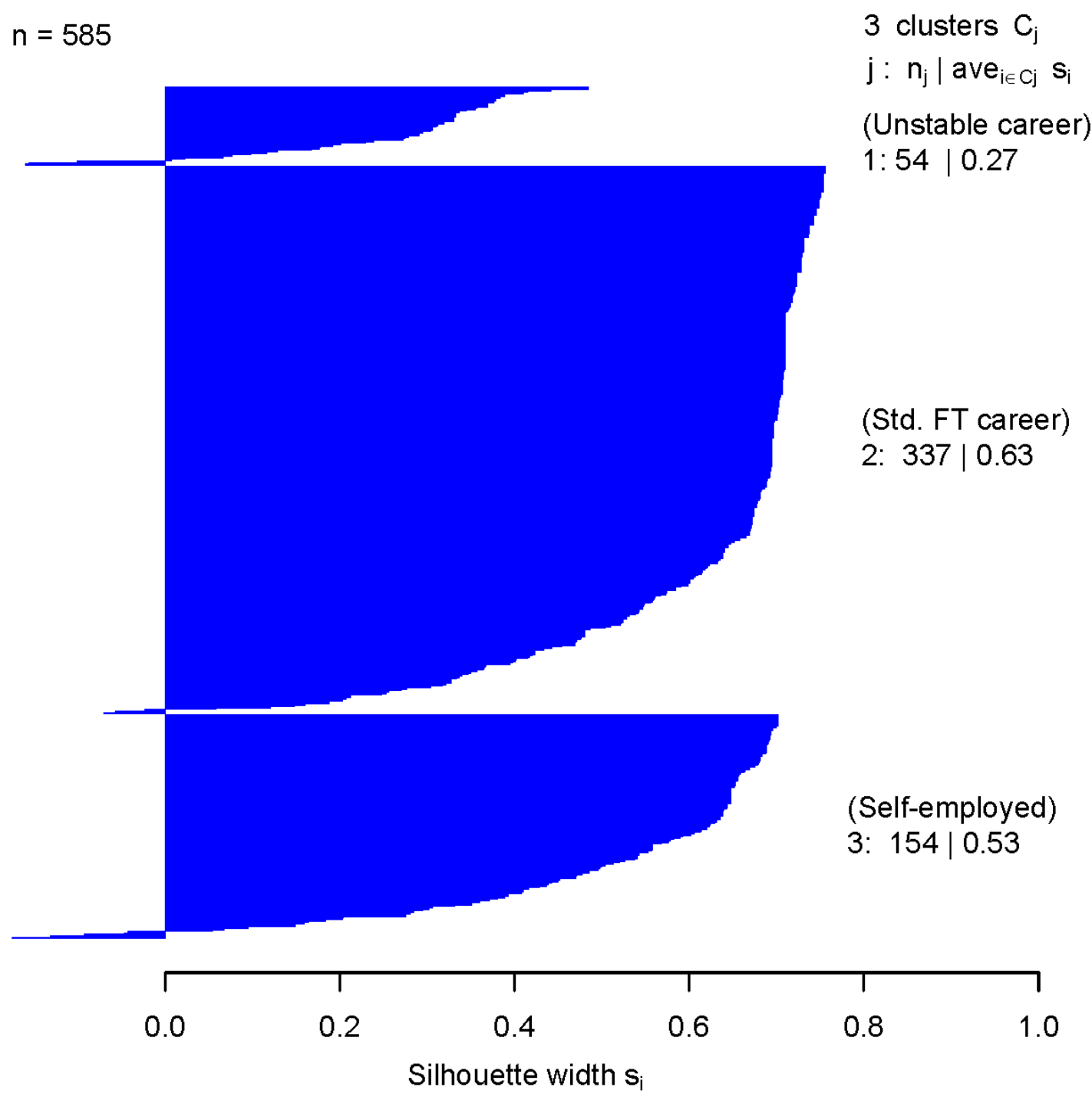

Average silhouette width : 0.57 


\section{[Supplementary materials (online only)]}

Supplementary material S1

Supplementary material S2
Sensitivity analysis on the clustering results

Additional analyses on model robustness and cohort heterogeneity 


\section{Supplementary material S1 Sensitivity analysis on the clustering results}

This section performs a sensitivity analysis on clustering results by choosing another sequence distance calculation algorithm. I use the Optimal Matching of spells (OMspell) algorithm with an expansion cost $e=0.5$ to calculate the distances matrix. Comparing to HAM, OMspell is more sensitive to the duration and the sequencing of spells (Studer \& Ritschard, 2016). It thus serves as the benchmark algorithm to test whether shifting the theoretical focus from timing to the duration and sequencing of states will significantly change the clustering results.

Figure S1.1 visualizes the clustering results using the OMspell distance calculation. Partitioning quality measures indicate an optimal solution of four clusters for women and three clusters for men. In a substantive sense, the three clusters for men from the OMspell are identical to those identified from the HAM. For women, one cluster that used to represent the "interrupted career" from HAM is replaced by another cluster from OMspell's result, which might be defined as "turbulence" as there is no clear pattern in the timing or sequencing of states except for the higher frequency of transitions. From a statistical point of view, this newly found cluster from OMspell is not appropriately identified because the majority of sequences within this cluster has a negative Silhouette width (cluster average Silhouette $=-0.02$ ), signaling a bad intra-cluster homogeneity. The performance of global-level indices also favors the result from HAM because it outperforms the OMspell in both the overall ASW and PBC for women's 4-cluster solution and men's 3-cluster solution (see Table A2 in the Appendix for the comparison of global-level and cluster-specific ASWs between these two solutions). 
Figure S1.1: Sensitivity analysis of clustering results using the OMspell algorithm.

\section{(a) Women}
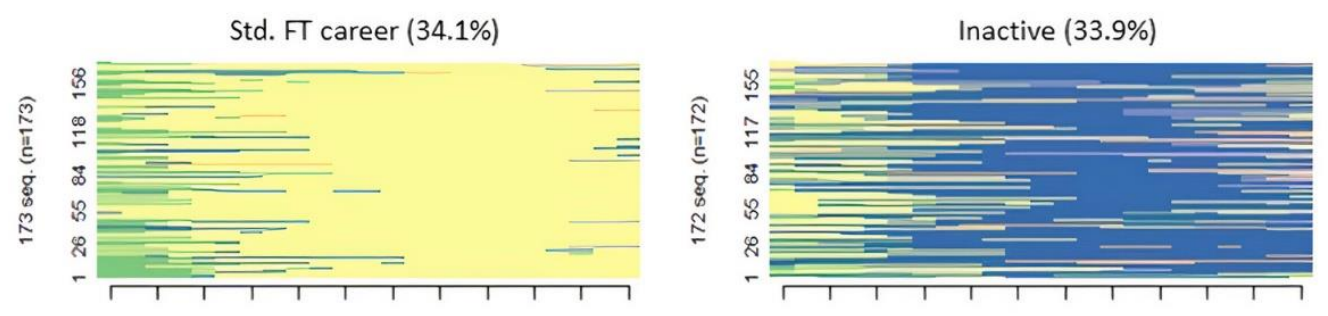

"Turbulence" (20.7\%)

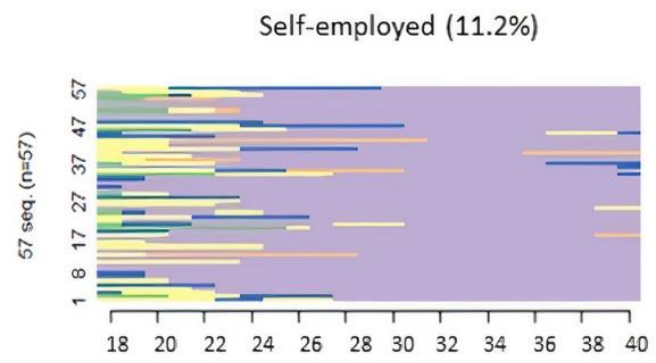

(b) Men

Std. FT career $(62.6 \%)$

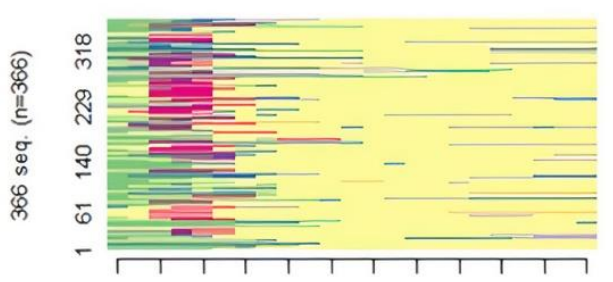

Unstable career (9.7\%)

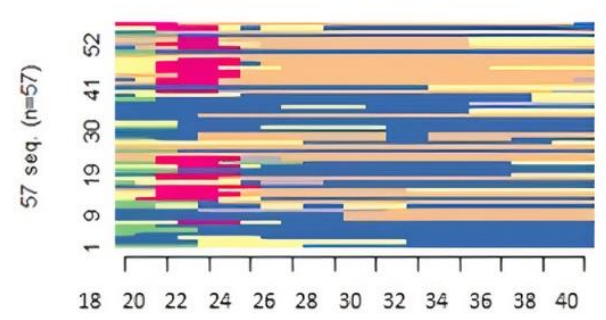

Self-employed (27.7\%)

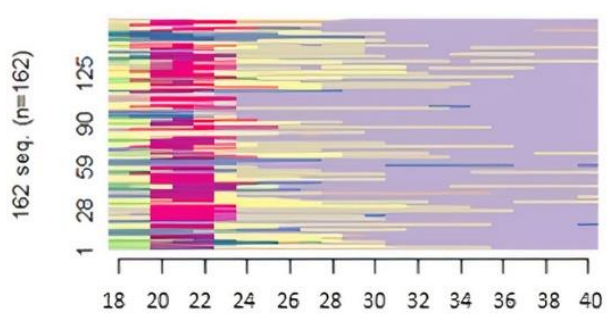

$\square$ Education

- Self-employment

Non-std employment

$\checkmark$ Std FT employment

Non-employment

Military service 
Supplementary material S2

Additional analyses on model robustness and cohort heterogeneity

In this section, I perform three additional analyses to supplement the main findings on the careerfertility quantum linkage. Building on the Poisson models in Table 3, the first analysis further controls for individual's highest educational level by age 40 (see Table S2.1). Theories have pointed out that receiving higher education not only facilitates people's successful career development in the long run (Buchmann \& Kriesi, 2011; Rosenfeld, 1992) but also influences his/her fertility behaviors in different cultural and welfare regimes (Begall \& Mills, 2013; Huinink \& Kohli, 2014; Lesthaeghe, 2010). Empirically speaking, one's educational level could serve as a crucial confounder in the relationship between careers and fertility and should be adjusted for in the regression models. However, the special feature of using longitudinal sequences as explanatory variables prevent the present study from including the education variable into the regression models because "in education" is an endogenous activity state forming the career sequences. In this context, adding the education variable that is endogenously determined by careers could introduce an overcontrol bias (Elwert \& Winship, 2014). Nevertheless, coefficient estimates from the additional analysis could serve as the lower bars of the career effects on fertility, which have been isolated from the education-related effects. According to Table S2.1, the career "ranking" of fertility quantum is similar to what I have found in Table 3. Clear messages from both analyses are the same: (1) having an inactive career positively associates with women's fertility; (2) having an unstable career negatively associates with men's fertility; (3) compared to standard full-time careers, self-employed careers are associated with higher fertility quantum for both sexes. While the estimated career differentials in women's fertility quantum have decreased, these gaps remain unignorable from a statistical point of view. For men, the negative association between having an unstable career and fertility becomes even stronger. In summary, the similar patterns found in Table S2.1 confirm the robustness of my main findings in Table 3.

Secondly, I model the parity-specific probabilities by age 40 using a set of logistic regressions. Comparing to the Poisson regressions of birth counts, the logistic regressions of parity-specific probabilities have the advantage of not making any assumption on the outcome variable distributions. This modeling strategy also allows a closer look into the parity 
composition behind the group average of fertility quantum. Figure S2.2 presents the predicted marginal probabilities of women's (S2.2-a) and men's (S2.2-b) parity status by age 40.

Table S2.1: Poisson regression models of the number of children for women and men by age 40 , conditioning on educational level by age 40 .

\begin{tabular}{|c|c|c|c|c|c|c|c|}
\hline & \multicolumn{3}{|c|}{ Model 1} & & \multicolumn{3}{|c|}{ Model 2} \\
\hline & $A M E$ & S.E. & p-value & & $A M E$ & S.E. & p-value \\
\hline Women's careers & & & & Men's career & & & \\
\hline Std. FT career & Ref. & & & Std. FT career & Ref. & & \\
\hline Interrupted & 0.251 & 0.121 & .038 & Self-employed & 0.270 & 0.103 & .009 \\
\hline Inactive & 0.577 & 0.147 & $<.001$ & Unstable career & -0.381 & 0.179 & .034 \\
\hline Self-employed & 0.241 & 0.135 & .074 & & & & \\
\hline Birth cohorts & & & & Birth cohorts & & & \\
\hline $1946-57$ & Ref. & & & 1946-57 & Ref. & & \\
\hline $1958-67$ & -0.315 & 0.105 & .003 & $1958-67$ & -0.539 & 0.103 & $<.001$ \\
\hline $1968-77$ & -0.847 & 0.137 & $<.001$ & $1968-77$ & -0.918 & 0.122 & $<.001$ \\
\hline $\begin{array}{l}\text { At least one parent has a } \\
\text { tertiary degree }\end{array}$ & 0.027 & 0.218 & .903 & $\begin{array}{l}\text { At least one parent has a } \\
\text { tertiary degree }\end{array}$ & -0.097 & 0.218 & .656 \\
\hline Ethnic minority & -0.220 & 0.150 & .144 & Ethnic minority & -0.017 & 0.209 & .936 \\
\hline $\begin{array}{l}\text { Family economic } \\
\text { background by age } 15\end{array}$ & -0.016 & 0.042 & .694 & $\begin{array}{l}\text { Family economic } \\
\text { background by age } 15\end{array}$ & 0.031 & 0.044 & .487 \\
\hline Educational level & & & & Educational level & & & \\
\hline Primary & Ref. & & & Primary & Ref. & & \\
\hline Secondary & -0.407 & 0.099 & $<.001$ & Secondary & -0.222 & 0.105 & .034 \\
\hline Tertiary & -0.729 & 0.156 & $<.001$ & Tertiary & -0.365 & 0.141 & .010 \\
\hline Observation & 507 & & & & 585 & & \\
\hline
\end{tabular}

Note: The table presents predictive average marginal effects (AMEs) from the Poisson regression models.

Bootstrapped standard errors with 200 bootstrap repetitions are calculated. p-values are calculated from the twotailed Wald tests.

For women working standard full-time, the highest probability is having 2 children $(\operatorname{Pr}=$ $0.415,95 \% C I=[0.353 ; 0.477])$. However, for women in other career trajectories, the highest probability is having 3 or more children by age 40 . Moreover, standard full-time women have the highest probabilities of staying childless $(\operatorname{Pr}=0.131,95 \% C I=[0.090 ; 0.171])$ or having only one child $(\operatorname{Pr}=0.121,95 \% C I=[0.083 ; 0.160])$ by age 40 . A sharp contrast in midlife parity status is observed especially between standard full-time and inactive women. My estimation shows that inactive women have the highest probability of having more than three children and the lowest probability of staying childless. In summary, these results are in line with the findings in Table 3. They further suggest that the negative association between women's standard fulltime career and fertility results mainly from a higher probability of staying childless and a lower 
Figure S2.2: Predicted marginal probabilities of women's and men's parity status by age 40 from parity-specific logistic regression models, by career type.
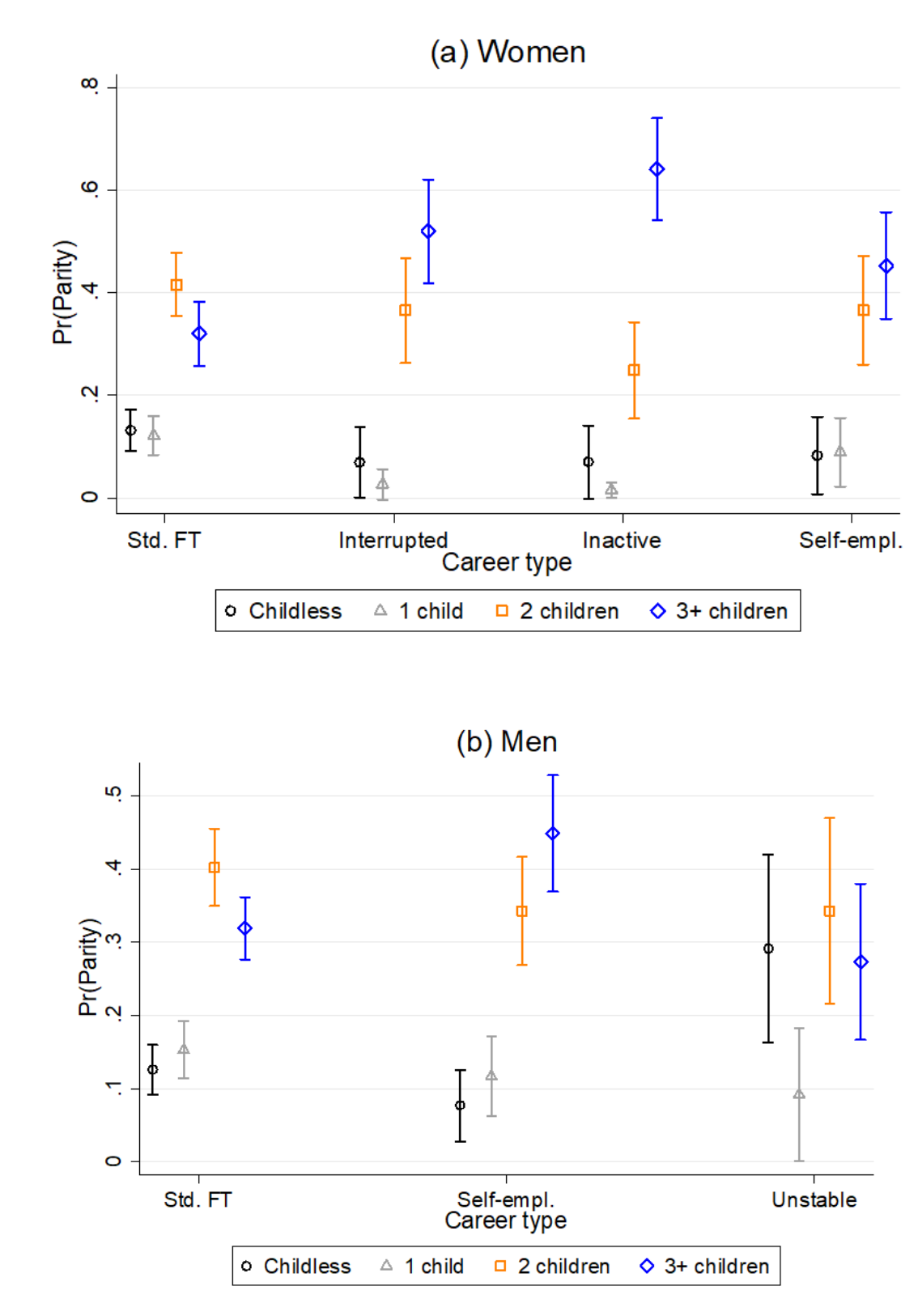

probability of progressing to higher-order births. Results in Figure S2.2-b also support the findings for men in Table 3. Comparing to standard full-time men, men of unstable careers have a higher probability of staying childless $(\operatorname{Pr}=0.291,95 \% C I=[0.163 ; 0.424])$ and lower probabilities of having two $(\operatorname{Pr}=0.343,95 \% C I=[0.216 ; 0.470])$ or three children $(\operatorname{Pr}=0.273$, $95 \% C I=[0.166 ; 0.380])$. I also found that self-employed men have the highest probability of having 3 or more children $(\operatorname{Pr}=0.449,95 \% C I=[0.369 ; 0.528])$ among Taiwanese men. These 
results confirm my findings that having an unstable career could depress men's fertility in Taiwan, while a self-employment career may enhance Taiwanese men’s fertility.

Finally, I include a set of interaction terms between career types and cohorts to the Poisson regression models to explore whether and how career-fertility relationships in Taiwan change across cohorts. Readers should notice that the following results are only supplementary and should be interpreted with caution due to small sample sizes in some career-cohort interaction categories. ${ }^{7}$ Figure S2.3 graphically summarizes the estimation results. According to Figure S2.3-a, comparing to being standard full-time employed, being economically inactive relates to women's significantly higher fertility across all cohorts, ranging from +0.66 children for the 1958-67 cohorts to +0.94 children for the 1946-57 cohorts. Meanwhile, the fertility surplus of self-employed women compared to standard full-time women has decreased over time, ranging from +0.60 children for the $1946-57$ cohorts to only +0.06 children for the $1968-$ 77 cohorts. Interestingly, having an interrupted career becomes more and more associated with higher fertility, particularly in the most recent cohorts. For men, Figure S2.3-b shows that the fertility surplus of self-employment comparing to a stander full-time career remains between +0.31 children for the $1946-57$ cohorts and +0.43 children for the $1968-77$ cohorts. More surprisingly, while having an unstable career does associate with lower fertility for men who were born after 1958, it does not negatively associate with men's fertility for the oldest cohorts. In a nutshell, my findings in Figure S2.3 indicate that Taiwanese people's "fertility rankings" by careers are largely stable over time, although the "fertility differentials" by careers have changed more significantly.

\footnotetext{
${ }^{7}$ For women, 5 out of the 12 career-cohort categories have a sample size fewer than 30 cases. For men, 3 out of the 9 career-cohort categories have a sample size fewer than 30 cases.
} 
Figure S2.3: Effects of career types on fertility quantum from Poisson regression models, by gender and birth cohorts.
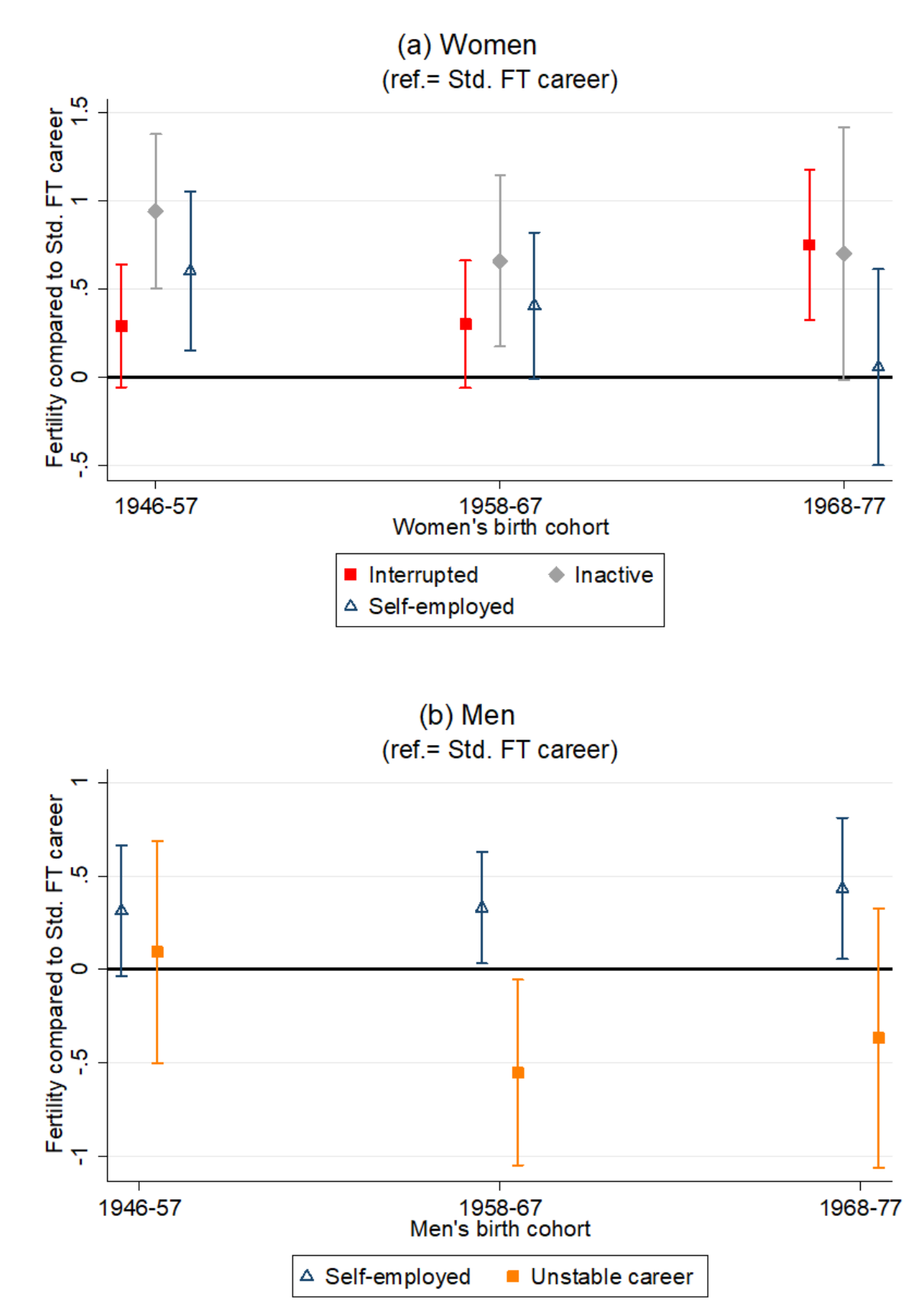

Note: Point estimates of the average marginal effects (AMEs) are calculated from the Poisson models, which control for individual's birth cohort, parental education, ethnicity, and family economic background by age 15 . Bootstrapped confidence intervals (95\% confidence level) from 200 repetitions are presented. 


\section{References}

Begall, K., and Mills, M. C. (2013). The influence of educational field, occupation, and occupational sex segregation on fertility in the Netherlands. European Sociological Review, 29(4), 720-742. https://doi.org/10.1093/esr/jcs051

Buchmann, M. C., \& Kriesi, I. (2011). Transition to adulthood in Europe. Annual Review of Sociology, 37(1), 481-503. https://doi.org/10.1146/annurev-soc-081309-150212

Elwert, F., and Winship, C. (2014). Endogenous selection bias: The problem of conditioning on a collider variable. Annual Review of Sociology, 40(1), 31-53. https://doi.org/10.1146/annurev-soc-071913-043455

Huinink, J., and Kohli, M. (2014). A life-course approach to fertility. Demographic Research, 30, 1293-1326. https://doi.org/10.4054/DemRes.2014.30.45

Lesthaeghe, R. (2010). The unfolding story of the Second Demographic Transition. Population and Development Review, 36(2), 211-251. https://doi.org/10.1111/j.17284457.2010.00328.X

Rosenfeld, R. A. (1992). Job mobility and career processes. Annual Review of Sociology, 18(1), 39-61. https://doi.org/10.1146/annurev.so.18.080192.000351

Studer, M., and Ritschard, G. (2016). What matters in differences between life trajectories: A comparative review of sequence dissimilarity measures. Journal of the Royal Statistical Society. Series A (Statistics in Society), 481-511. https://doi.org/10.1111/rssa.12125 